\title{
Failure characteristics of a dual-phase steel sheet
}

\author{
Oscar Björklund and Larsgunnar Nilsson
}

\section{Linköping University Post Print}

\section{Tweet}

N.B.: When citing this work, cite the original article.

Original Publication:

Oscar Björklund and Larsgunnar Nilsson, Failure characteristics of a dual-phase steel sheet, 2014, Journal of Materials Processing Technology, (214), 1190-1204.

http://dx.doi.org/10.1016/j.jmatprotec.2014.01.004

Copyright: Elsevier

http://www.elsevier.com/

Postprint available at: Linköping University Electronic Press

http://urn.kb.se/resolve?urn=urn:nbn:se:liu:diva-105209 


\title{
Failure characteristics of a dual-phase steel sheet
}

\author{
Oscar Björklund*, Larsgunnar Nilsson \\ Division of Solid Mechanics, Linköpings University, SE-581 83 Linköping, Sweden
}

\begin{abstract}
Failure in ductile sheet metal structures is usually caused by one, or a combination of, ductile tensile fractures, ductile shear fractures or localised instability. In this paper the failure characteristics of the high strength steel Docol 600DP are explored. The study includes both experimental and numerical sections. In the experimental sections, the fracture surface of the sheet subjected to Nakajima tests is studied under the microscope with the aim of finding which failure mechanism causes the fracture. In the numerical sections, finite element (FE) simulations have been conducted using solid elements. From these simulations, local stresses and strains have been extracted and analysed with the aim of identifying the fracture dependency of the stress triaxiality and Lode parameter.
\end{abstract}

Keywords: sheet metal failure, forming limit, instability, ductile tensile fracture, ductile shear fracture

\footnotetext{
${ }^{*}$ Corresponding author. Tel.:+46-13 28 1111; fax:+46-13 282717.

Email address: oscar.bjorklund@liu.se (O. Björklund)
}

\section{Introduction}

It is important to understand the failure process in high-strength sheet metals in order to predict their mechanical responses using finite element (FE) simulations. Teirlinck et al. (1988) describes four failure phenomena observed in uniaxial tension specimens: plastic failure, ductile fracture, shear fracture, and cleavage and brittle intergranular fracture. It should be noted that failure due to cleavage and brittle intergranular fracture, is considered as a brittle fracture which not will be covered here. Failure is defined as the local loss of load-carrying capacity, while fracture is defined as material separation. Consequently, failure incorporates the term fracture but may also be caused by other phenomena which do not include material separation e.g. material and geometrical instabilities.

The term plastic failure used in Teirlinck et al. (1988), is often generalised to represent any sheet instability, cf. Lademo et al. (2009). All fractures in ductile sheet metals are considered to be ductile. Therefore, the notation ductile tensile fracture and ductile shear fracture have been introduced in this study. Ductile fracture is, from this point, used both for the ductile tensile and the ductile shear fracture. The ductile fracture process is characterised by initiation, growth and coalescence of voids in the material, the loaded area is reduced, and eventually 
material fracture occurs. The fracture surface is characterised by the presence of dimples. The shape of these dimples is influenced by the direction of the deformation. In a tensile fracture, dimples usually have a circular appearance while in a shear dominated fracture the dimples have an elongated elliptical shape, see Metals Handbook (1974). Furthermore, the ductile shear fracture surface consists of fine, closely-spaced dimples which are much wider than they are deep, see Garrison Jr and Moody (1987). Weck and Wilkinson (2008) studied the fracture characteristics of specimens with laser-drilled holes in different orientations. They concluded that when the holes are located parallel to the loading direction, coalescence occurred by internal necking of the ligaments between the holes. However, when the holes are oriented at an inclined direction to the loading direction, coalescence occurred by a shearing process. Ductile shear fracture can be caused either by extensive slip on the activated slip planes, see Dieter (1986), or as a result of void nucleation in slip bands. Both these mechanisms are favoured by shear stresses. When voids nucleate in slip bands, the loaded area is reduced such that plastic flow localises there. Continued shear increases the area of voids until separation occurs. Furthermore, as stated by Teirlinck et al. (1988) "Voids which extend in shear need not increase in volume, so shear fracture is less pressure-dependent than ductile fracture, though it remains more pressure-dependent than purely-plastic failure". The ductile shear fracture can be either a through-thickness shear fracture, see e.g. Björklund et al. (2013), or an in-plane shear fracture, see e.g. Li et al. (2010). Instabilities arise when the strain hardening can no longer compensate for the reduction in load carrying area. Hence, strain localises at a small region and the material fails due to ductile tensile or ductile shear fracture. By examining the fracture surface under a microscope, it is most often noted that different fracture types are present in different areas of the specimen, cf. Li et al. (2011). For example, in the tensile test of a round specimen the failure process is initiated by an instability followed by a ductile tensile fracture in the centre of the specimen before finally complete separation occurs by shear, cf. Hosford (2005).

Numerical studies of the deformation of cylindrical voids by e.g. McClintock (1968) and spherical voids by e.g. Rice and Tracey (1969) have shown that the growth-rate depends on the stress state, and in particular the stress triaxiality. Furthermore, as stated in Lemaitre and Chaboche (1990), the nucleation and growth of voids in isotropic material depends not only on the first two stress invariants, as expressed by the stress triaxiality, but also on the third stress invariant. The dependency on the third stress invariant has been shown numerically by, for example, Zhang et al. (2001). This was achieved by using the Lode parameter, see Lode (1926), which incorporates the third stress invariant. Subsequently the influence of both the stress triaxiality and the Lode parameter has been studied numerically, e.g. Barsoum and Faleskog (2007a) and experimentally, e.g. Barsoum and Faleskog (2007b).

The reduction in load-carrying area due to void growth and coalescence leads to material softening. In damage models, material softening is coupled to the constitutive relation either by a porous plasticity, cf. Gurson (1977), or by continuum damage mechanics, cf. Lemaitre (1985). In most fracture criteria, on the 
other hand, the softening effect is not included in the constitutive relation. Several phenomenological criteria have been proposed for predicting ductile fracture. The Cockroft and Latham (1968) criterion is a modified maximum plastic work criterion based on the maximum principal stress. Johnson and Cook (1985) developed a criterion that depends on stress triaxiality, strain rate, temperature and equivalent plastic strain. Bai and Wierzbicki (2010) introduced a ductile fracture criterion based on a modification of the Mohr-Coulomb criterion, henceforth denoted as the MMC criterion. In the criterion presented by Aretz et al. (2011), a loading mode parameter was introduced that classifies the stress state from pure tensile to pure compression. Gruben et al. (2012) presented an extension of the Cockroft-Latham criterion incorporating both the maximum principal stress and the maximum shear stress. Lou et al. (2012) presented another fracture criterion, which combines the effect of stress triaxiality and maximum shear stress. Lou and Huh (2013a) reformulated this criterion to incorporate Lode parameter dependency.

Prediction of sheet instability due to localisation has been studied by the use of analytical models for the negative side of the forming limit diagram (FLD), see Hill (1952), and for the positive side of the FLD, see Swift (1952). Hora et al. (1996) presented a more general analytical instability model which is valid both in the positive and negative domains of the FLD. For a recent review on sheet instability, see Aretz (2004). Also instability criteria based on non-homogeneous sheets have been used to predict localisation, see Marciniak and Kuczyński (1967). Detailed finite element (FE) models with elasto-plastic or elasto-viscoplastic constitutive laws can be used to capture instability phenomena in details, cf. Lademo et al. (2004).

As an alternative to the phenomenological models used to predict fracture and instabilities, the experimental forming limit curve (FLC) has been a popular mean. However, the FLC is a useful locus of failure only for proportional strain paths since the FLC depends on the strain history, cf. Hosford and Cadell (1993). In order to address the problem of path dependency in strain-based FLDs, stressbased FLDs have been proposed, see e.g. Stoughton (2000). The stress-based FLDs have been argued to be independent of the strain path. One problem with the stress-based FLCs is the reduction of hardening, which causes a considerable change in strain close to necking. This effect makes it hard to visualise the margin of safety in the stress diagram. A cure for this is to visualise the FLC in a diagram of the effective plastic strain which is directly linked to the stress by the hardening curve, see e.g. Stoughton and Yoon (2012).

Failure and fracture of metals have been studied extensively. A review of some frequently used fracture criteria and the issue of how to calibrate them was presented by Wierzbicki et al. (2005). Pedersen et al. (2008) studied the formability of AlMgSi alloys with different grain structures under linear loading paths. Lademo et al. (2009) predicted fracture in an aluminium alloy subjected to the Nakajima tests by use of Cockroft-Latham fracture criterion combined with an FE-based prediction of instabilities. Mirone and Corallo (2010) used the maximum shear stress criterion, the Bao and Wierzbicki (2004) criterion and an evolution 
of the later criterion by Wierzbicki et al. (2005) to study the influence of both the stress triaxiality and the Lode parameter on fracture in four different metals. Luo and Wierzbicki (2010) predict shear fracture during the stretch-bending of dual-phase steel using the MMC criterion. The special case of shear fracture, due to the high-curvature die radii, in sheet forming operations of three dual-phase steels was studied by Kim et al. (2011). Dunand and Mohr (2011) compared a shear modified Gurson criterion by Nielsen and Tvergaard (2009), and the MMC criterion in predictions of fracture over wide range of stress states for a TRIP780 steel. Stoughton and Yoon (2011) predicted fracture during opening of a food-can using a plane stress assumption and the maximum shear stress criterion. Gruben et al. (2011) studied the fracture characteristics of a cold-rolled dual-phase steel using FE simulations and digital image correlation (DIC). In Gruben et al. (2013) DIC was used to identify the onset of instability and fracture in both MarciniakKuczyński and Nakajima tests of a cold-rolled dual-phase steel. Ebnoether and Mohr (2013) studied the fracture of low carbon steel sheets using the original Mohr-Coulomb criterion and the MMC. Aretz et al. (2013) predicted fracture during the forming of an AA 5182 aluminium alloy.

In this paper the fracture of Docol 600DP, a dual phase high strength steel, is studied. The major objective of this study is to identify the fracture that occurs in Nakajima tests designed for different straining situations. An extensive test programme has been carried out, which is presented in Section 2. The different failures are observed in microscope as reported in Section 2.1. A brief discussion of the constitutive equation utilised follows in Section 3, and an identification of key parameters for failure representation is given in Section 4 . The numerical simulations are briefly described in Section 5 followed by a validation of the simulation models. Finally, findings and results are discussed in Section 7.

\section{Experimental work}

The high strength steel (HSS) Docol 600DP is a dual phase steel consisting of about $75 \%$ ferrite and $25 \%$ martensite, in which the microstructure is produced by heat treatment, see Olsson et al. (2006). The nominal thickness of the steel sheets studied here was $1.48 \mathrm{~mm}$ with a standard deviation measured to be $5.0 \mu \mathrm{m}$. Tensile, plane strain (notched tensile test) and in-plane shear tests, with geometries according to Fig. 1, were performed in an INSTRON 5582 testing machine with a $100 \mathrm{kN}$ load cell. The loading velocity has been selected such that a quasistatic loading condition is obtained, i.e. a strain rate of approximately $10^{-4} s^{-1}$. A representative fracture for each specimen type can be seen in Fig. 2. Both the tensile and plane strain specimens fractured after maximum load and the fracture is initiated at the specimen centre, see Fig. 3. Regarding the shear specimen the maximum load occurs just before a complete material separation and it is hard to identify the location of the fracture initiation. In Björklund et al. (2013) the fracture was assumed to start at the edge of the specimen, since the maximum value of the fracture parameter according to Cockroft and Latham (1968) was found at this location. However, in Gruben et al. (2011) a similar in-plane shear specimen 
was investigated where the fracture was assumed to initiate at the centre of the specimen. Lou and Huh (2013b) studied another type of in-plane shear specimen and assumed that fracture is initiated at the location of maximum equivalent plastic strain. In their study the maximum equivalent plastic strain at fracture occurred at a small distance from the edge of the specimen. However, for the specific specimen geometry and material in this study the maximum equivalent plastic strain at fracture occurs at the edge of the specimen. In this work stress and strain states in both the centre and at the edge of the specimen have been studied.

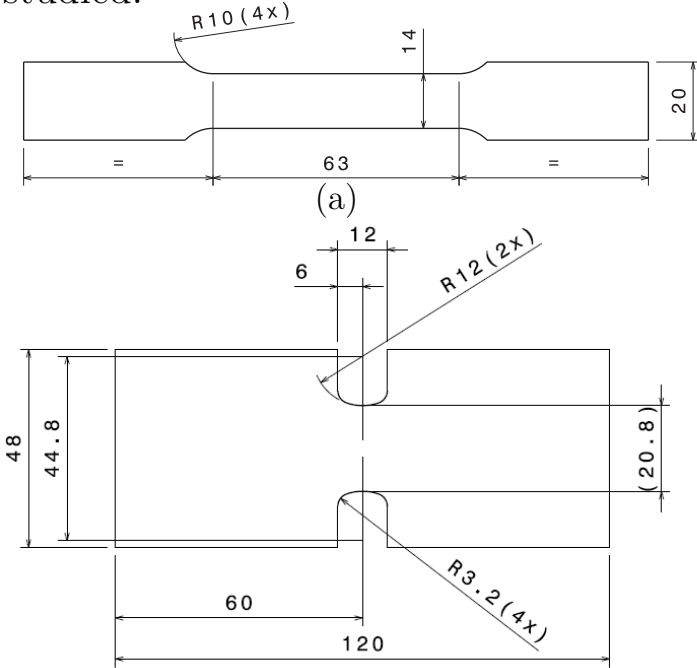

(b)

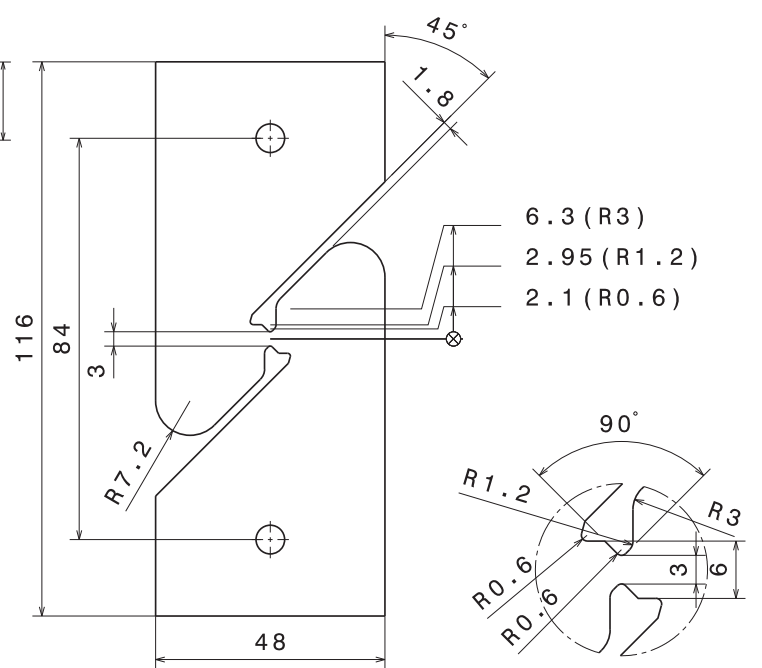

(c)

Figure 1: Geometry of (a) the tensile specimen, (b) the plane strain specimen and (c) the shear specimen. Dimensions in $\mathrm{mm}$.

A number of Nakajima tests, see ISO (2008), have been conducted. The tests were made for different specimen geometries, see Fig. 4, to produce strain states in the first quadrant $\left(\varepsilon_{1}>0, \varepsilon_{2}>0\right)$ of the forming limit diagram (FLD). The Nakajima tests were performed in an Interlaken ServoPress 150, with a punch diameter of $100 \mathrm{~mm}$. The clamping force was limited to $700 \mathrm{kN}$, and the punch motion was set at $1 \mathrm{~mm} / \mathrm{s}$. The specimens were treated with lubrication oil and three layers of plastic film in order to reduce friction between the punch and sheet. A $2 \mathrm{~mm}$ grid was etched on the top sheet surface of the specimens to facilitate a subsequent optical evaluation of the strains by an AutoGrid 4.1 Strain Analysis System, which uses information from four cameras recording 30 images per second during the test. The image just before fracture was used to evaluate the limit strains. Since the grid captures the strains close to the fracture, these strains may be beyond the limit of localisation. Consequently a polynomial fit method similar to the one described by Bragard et al. (1972) was used to evaluate the limit strains at the onset of localisation. The strains along a few lines across the localisation band were evaluated. For each line the strains inside the localisation zone were then excluded and a polynomial was fitted to the remaining strains in order to find the limit strain causing localisation. For the Nakajima specimens, the fracture was initiated close to the centre of the specimen. 


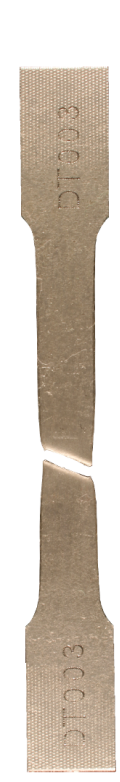

(a)

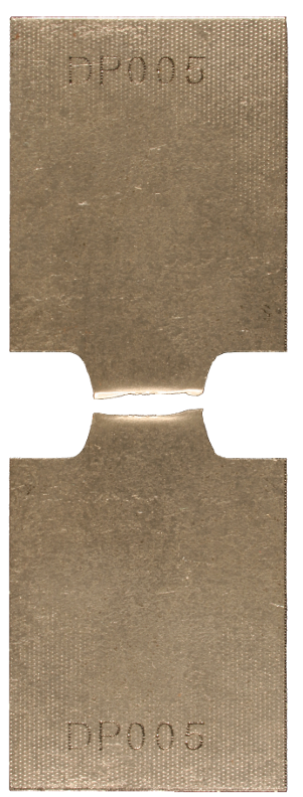

(b)

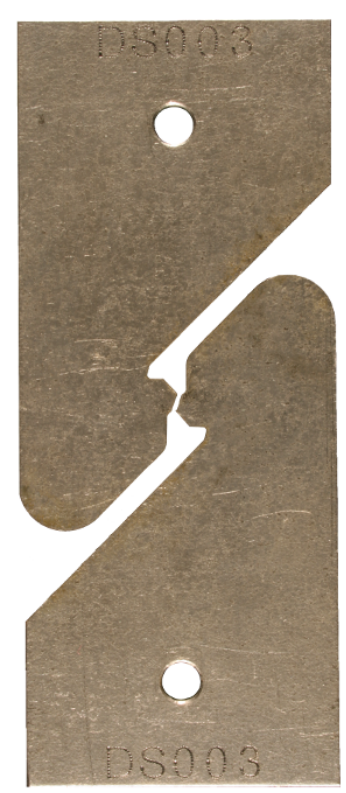

(c)

Figure 2: Fracture of the (a) tensile specimen, (b) plane strain specimen and (c) in-plane shear specimen.

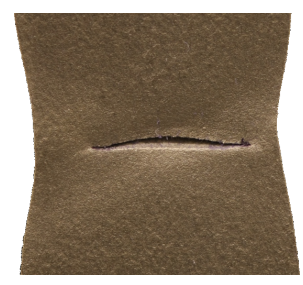

(a)

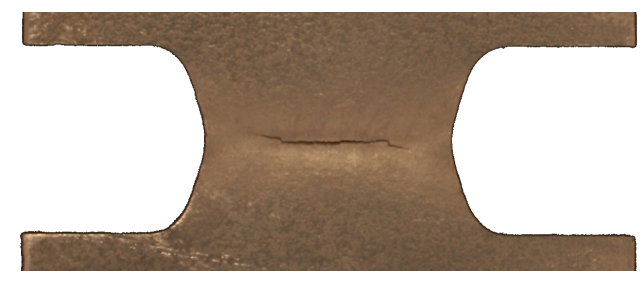

(b)

Figure 3: Fracture initiation in the (a) tensile specimen and (b) plane strain specimen.

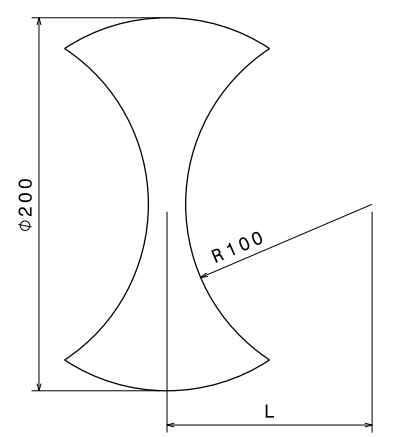

(a)

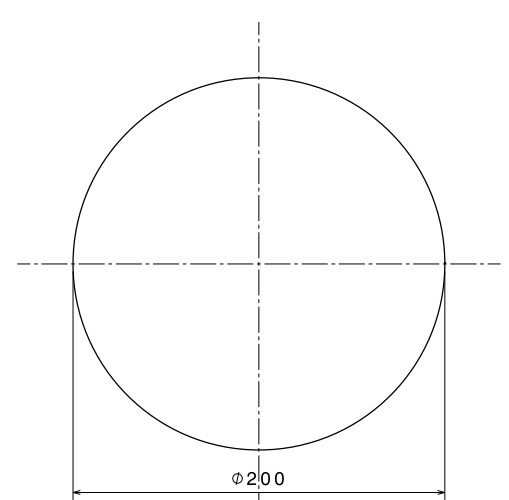

(b)

Figure 4: Geometry of the Nakajima specimens (a) waist 60, 80, 100, 120, 130 and $140 \mathrm{~mm}$ ( L=130,140,150,160,165 and $170 \mathrm{~mm}$ ) and (b) circular. Dimensions in $\mathrm{mm}$. 


\subsection{Identification of failure type in the Nakajima tests}

In order to identify the type of failure appearing in the Nakajima tests, the fractures have been studied under a microscope. A scanning electron microscope (SEM) and a light microscope (LM) have been used to study the fracture appearance, see Fig. 5. In order to reveal the microstructure of the specimens, they were treated with a $3 \%$ Nital solution for 5 seconds. From the final fracture of all specimens it is observed that the fracture surface is inclined compared to the main loading direction, see Fig. 6, which indicates that the final fracture is driven by through thickness shearing. However, the main interest of this study is the initiation of the failure and not the appearance of the final fracture. Failure initiation has been categorised into, thickness instability, ductile tensile fracture and ductile shear fracture. If a pronounced thickness reduction is observed close to the fracture surface, the failure has been defined as a thickness instability. Otherwise, detailed SEM studies have been conducted in order to identify the location of fracture initiation. From the centre part of the specimens, where the fracture was assumed to initiate, two different appearances of fracture surfaces have been observed. If the fracture surface shows a rough appearance, the fracture has been defined as a ductile tensile fracture. On the other hand if the surface is flat, the fracture has been defined as a ductile shear fracture. Some additional differences were noted from large magnification LM studies. The grain orientation remote to the fracture is aligned in the main loading direction of all Nakajima specimens. However, close to the fracture surface some specimens show a slight rotation of the grains, and this rotation is assumed to occur due to a ductile shear fracture.

Measurements of sheet thickness near the fracture location have been made using LM. Thickness strain has been evaluated from these measurements, see Fig. 7. For the specimens with a waist of $60 \mathrm{~mm}$ to $120 \mathrm{~mm}$, there is a rapid decrease in the strain near the fracture location which indicates that a thickness instability occurs prior to fracture. For the specimens with larger waists, $130 \mathrm{~mm}$ up to circular, this reduction is not as significant and either a ductile tensile or ductile shear fracture occurs without a prior instability. The relationship between the thickness strain at the location of fracture and approximately $1.5 \mathrm{~mm}$ remote from this location is presented in Table 1. A significant difference between the strain ratios for the specimens with waists of $60 \mathrm{~mm}$ to $120 \mathrm{~mm}$ and the wider ones can be observed.

A closer view of fracture surfaces is required to identify the different fracture types in the three specimens in which instability was not detected. The fracture surfaces of the specimens with waists of $130 \mathrm{~mm}, 140 \mathrm{~mm}$ and the circular specimen shown using LM are presented in Fig. 8. The orientation of the grains remote to the fracture location is aligned in the length direction. In the case of the $130 \mathrm{~mm}$ waist specimen, it can be observed that the grain orientation is rotated to become more parallel to the fracture surface close to it, see the indicator lines in Fig. 8(a). In the case of the $140 \mathrm{~mm}$ and circular specimens there is no such rotation, see Figs. 8(b) and 8(c). These observations indicate that the fracture in the specimen with a $130 \mathrm{~mm}$ waist is a ductile shear fracture and that the fractures in the specimens with a waist of $140 \mathrm{~mm}$ and in the circular are ductile tensile fractures. 
Observations of the fracture surfaces using an SEM also reveal a large variation in fracture characteristics. In large magnification, all specimens show ductile fracture characteristics. However, with a moderate magnification of 300 times there is a significant difference in fracture appearance, see Fig. 9. The fracture surface in the specimen with a waist of $130 \mathrm{~mm}$ appears flat, which indicates a ductile shear fracture, see Fig. 9(a). In the case of the circular specimen, the fracture surface is rough, which indicates a ductile tensile fracture, see Fig. 9(b). The specimen with a waist of $140 \mathrm{~mm}$ appears similar to the circular specimen.

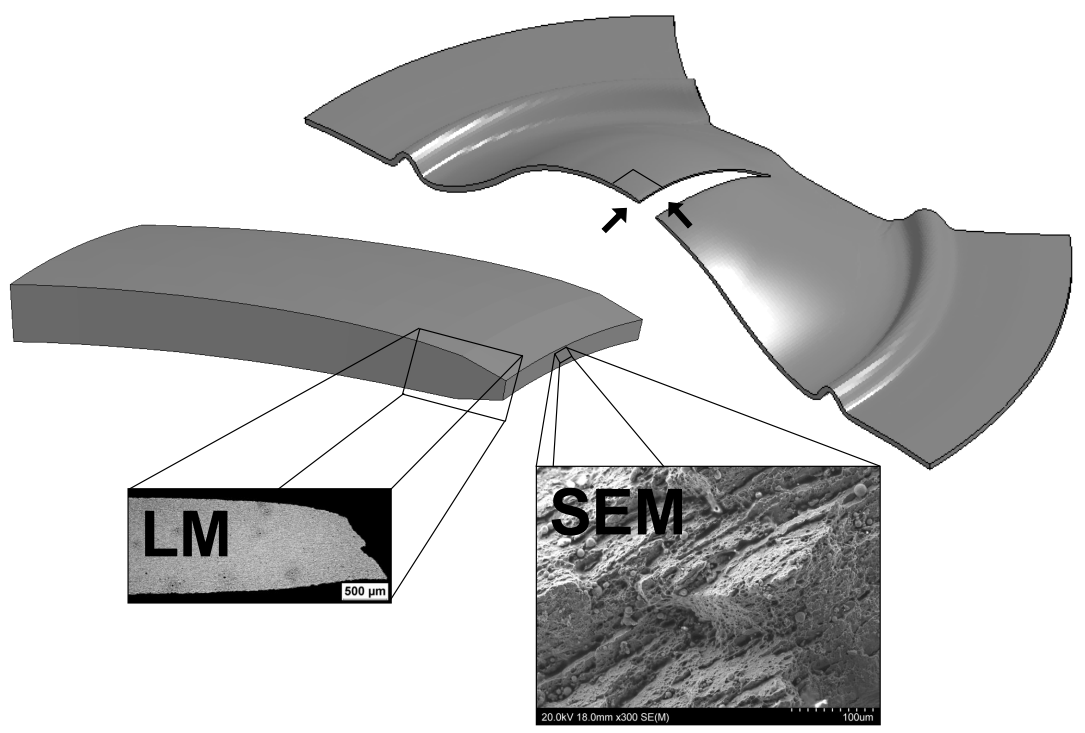

Figure 5: Illustration of how the different microscopic pictures are received from scanning electron microscope (SEM) and light microscope (LM).

Table 1: Strain ratio obtained from measurement of the Nakajima tests.

\begin{tabular}{lc}
\hline Specimen & Strain ratio \\
\hline $60 \mathrm{~mm}$ & 2.12 \\
$80 \mathrm{~mm}$ & 2.16 \\
$100 \mathrm{~mm}$ & 3.35 \\
$120 \mathrm{~mm}$ & 2.22 \\
$130 \mathrm{~mm}$ & 1.37 \\
$140 \mathrm{~mm}$ & 1.20 \\
Circular & 1.34 \\
\hline
\end{tabular}




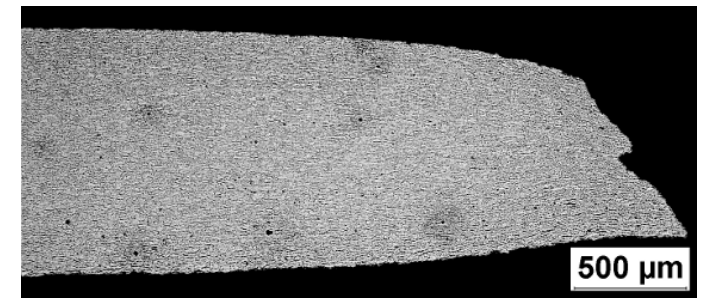

(a)

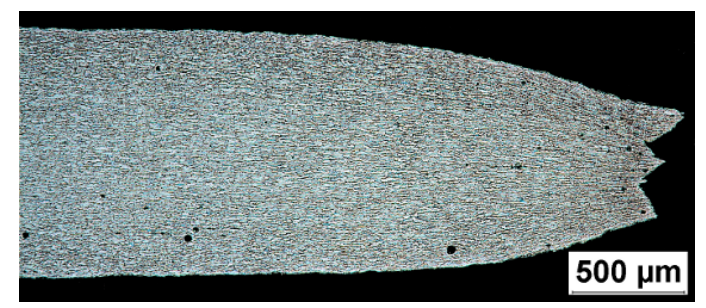

(c)

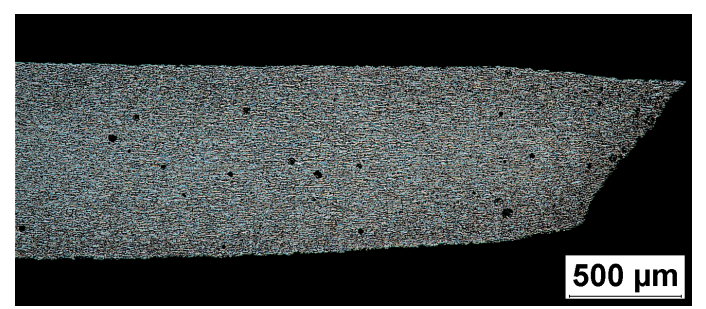

(e)

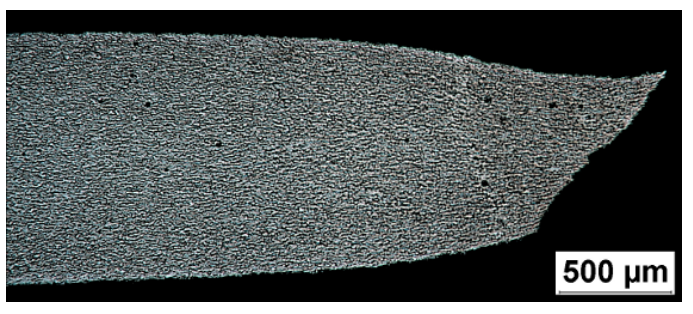

(b)

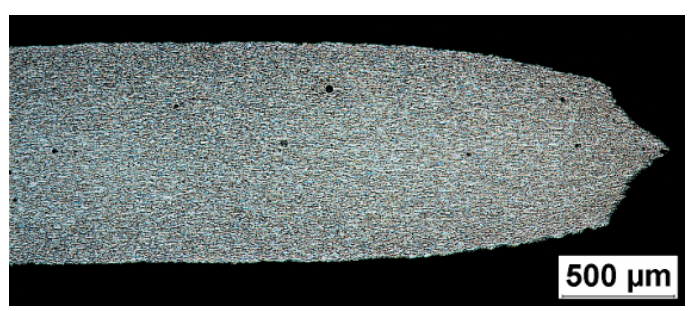

(d)

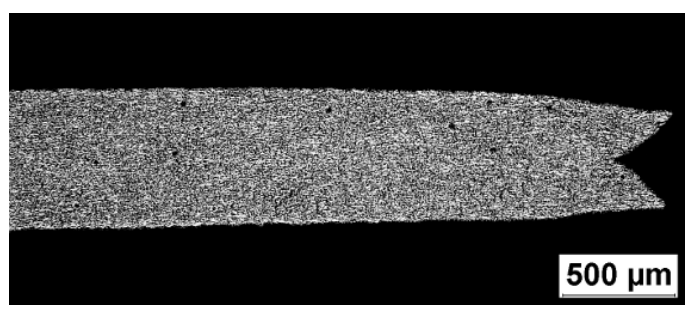

(f)

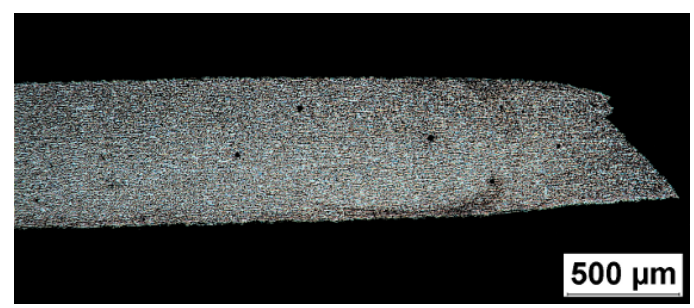

(g)

Figure 6: Microscopic of fractures in Nakajima test specimens: (a) $60 \mathrm{~mm}$ waist, (b) $80 \mathrm{~mm}$ waist, (c) $100 \mathrm{~mm}$ waist, (d) $120 \mathrm{~mm}$ waist, (e) $130 \mathrm{~mm}$ waist, (f) $140 \mathrm{~mm}$ waist, and (g) circular. 


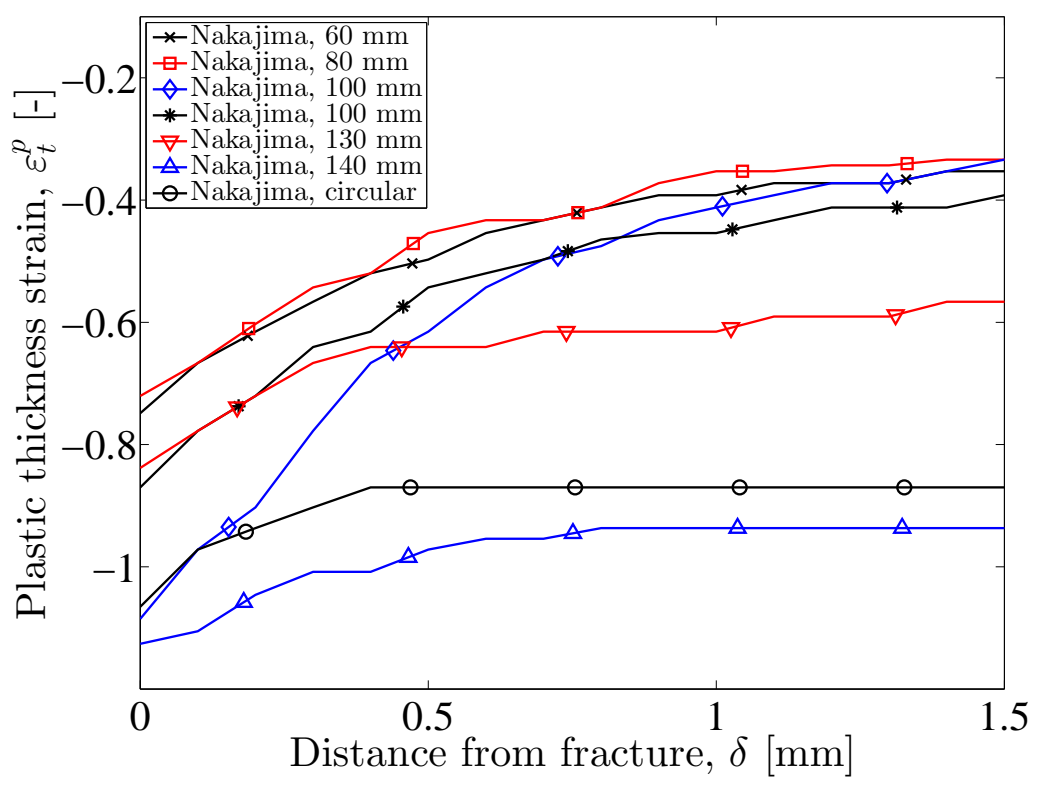

Figure 7: Distribution of the plastic thickness strain at fracture for the Nakajima test experiments.

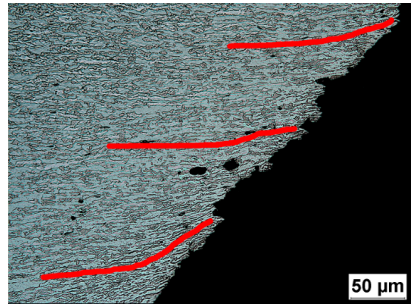

(a)

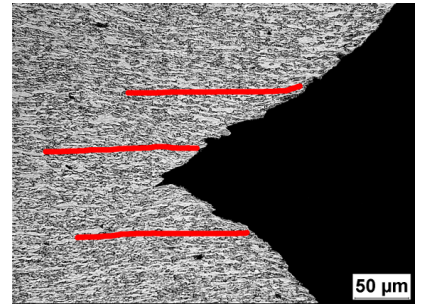

(b)

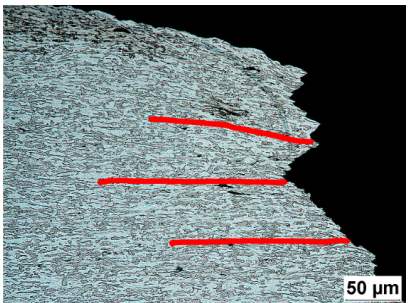

(c)

Figure 8: Close-up of microscopic of fractures in Nakajima test specimens: (a) 130 mm waist, (b) $140 \mathrm{~mm}$ waist (c) circular.

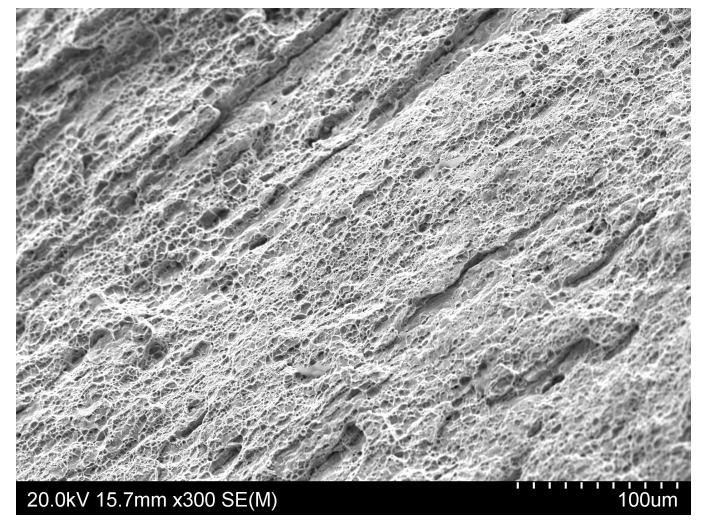

(a)

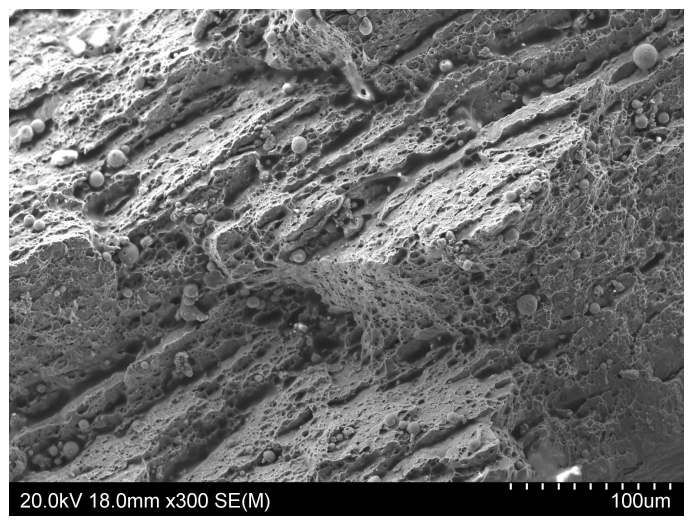

(b)

Figure 9: SEM picture of the fracture surface in Nakajima test specimens: (a) 130 mm waist and (b) circular. 


\section{Constitutive model}

The material used in this study has previously been investigated in Larsson et al. (2011). An associated plasticity theory was used with an effective stress for anisotropic plane stress according to Aretz (2005) and mixed isotropic and kinematic hardening. In this study solid elements and an isotropic effective stress according to Hershey (1954) has been used, i.e.

$$
\bar{\sigma}(\boldsymbol{\sigma})=\left[\frac{1}{2}\left(\left|\sigma_{1}-\sigma_{2}\right|^{m}+\left|\sigma_{2}-\sigma_{3}\right|^{m}+\left|\sigma_{3}-\sigma_{1}\right|^{m}\right)\right]^{1 / m}
$$

where $\sigma_{1}, \sigma_{2}$ and $\sigma_{3}$ are the principal stresses and $m$ is the yield surface exponent. The effective stress according to von Mises and Tresca can be obtained as a special case of Eq. (1) by changing the yield surface exponent, i.e. von Mises $m=2$ or 4 and Tresca $m=1$ or $\infty$. A comparison between the effective stress according to Aretz (2005) and Hershey (1954) is found in Fig. 10. Associated plasticity and isotropic hardening are used and the yield function is given in

$$
f=\bar{\sigma}(\boldsymbol{\sigma})-\sigma_{f}\left(\bar{\varepsilon}^{p}, \dot{\bar{\varepsilon}}^{p}\right)
$$

where $\bar{\sigma}$ and $\sigma_{f}$ are the effective and flow stresses, respectively. A multiplicative strain rate dependency has been assumed so that the flow stress is given by

$$
\sigma_{f}\left(\bar{\varepsilon}^{p}, \dot{\bar{\varepsilon}}^{p}\right)=\sigma_{y}\left(\bar{\varepsilon}^{p}\right) H\left(\dot{\bar{\varepsilon}}^{p}\right)
$$

where $\sigma_{y}$ and $H$ are the yield stress and the strain rate sensitivity (SRS) function, respectively. An extended Voce Law, see Voce (1948), was fitted to the hardening data from the tensile test up to a transition strain chosen close to diffuse necking. After this transition an extrapolation using the Hollomon Law, see Hollomon (1945), has been used. The analytic hardening function can be expressed as

$$
\sigma_{y}\left(\bar{\varepsilon}^{p}\right)= \begin{cases}\sigma_{0}+\sum_{i=1}^{2} Q_{i}\left(1-e^{-C_{i} \bar{\varepsilon}^{p}}\right) & \bar{\varepsilon}^{p} \leq \varepsilon^{t} \\ A+B\left(\bar{\varepsilon}^{p}\right)^{C} & \bar{\varepsilon}^{p}>\varepsilon^{t}\end{cases}
$$

where $\sigma_{0}, Q_{i}, C_{i}, A, B$ and $C$ are material constants and $\varepsilon^{t}$ is the transition point between the extended Voce and Hollomon hardening. As SRS function, a modified power law function has been used, see e.g. Tarigopula et al. (2006).

$$
H\left(\dot{\bar{\varepsilon}}^{p}\right)=\left(1+\frac{\dot{\bar{\varepsilon}}^{p}}{\dot{\varepsilon}_{0}}\right)^{q}
$$

where $\dot{\varepsilon}_{0}$ and $q$ are material constants. The strain rate properties of the Docol 600DP material have been studied by Larsson (2012). In this study the findings in Larsson et al. (2011) and Larsson (2012) have been adopted and the parameters of the constitutive formulation are presented in Table 2. The 
isotropic hardening has been adjusted to experimental data from the transversal direction (TD), i.e. $90^{\circ}$ to the rolling direction (RD). Furthermore, simulations without strain rate effects, denoted as "no SRS", have also been conducted and in this case the yield stress has been scaled with the reference strain rate $H_{\text {ref }}\left(\dot{\bar{\varepsilon}}^{p}=10^{-4}\right)=1.0088$.

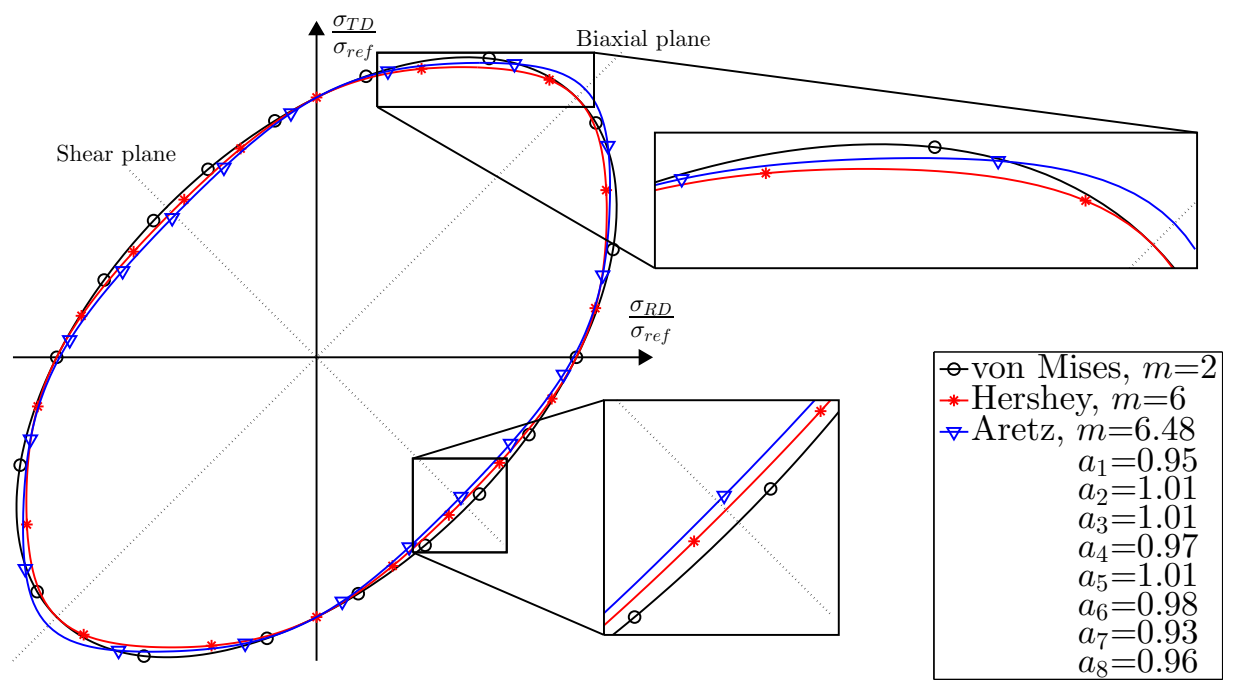

(a)

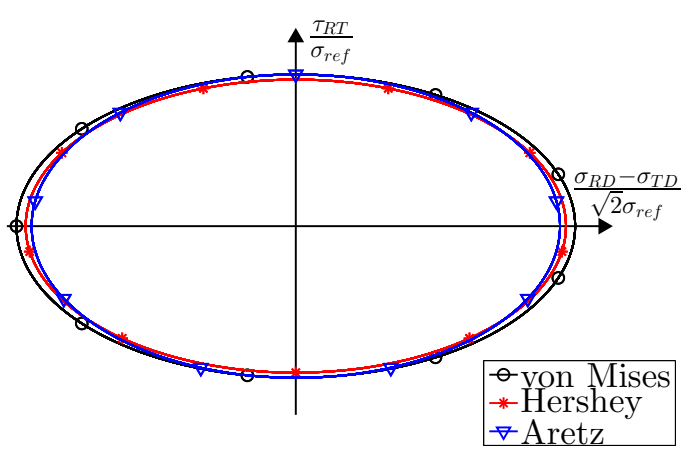

(b)

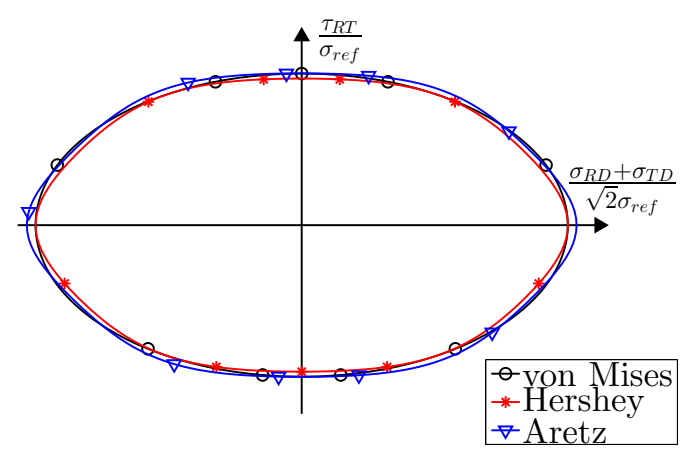

(c)

Figure 10: Yield loci in different planes, $R D$ and TD indicate the rolling and transversal directions, respectively. The index RT is the in-plane shear component. The parameters representing the Aretz locus are taken from Larsson et al. (2011) ( $m=6.48$ and $a=[0.95,1.01,1.01,0.97,1.01,0.98,0.97,0.96])$ and an exponent of $m=6$ has been used for the Hershey effective stress. (a) yield surface for plane stress assumption, (b) shear plane and (c) biaxial plane.

\section{Failure representation}

The classical forming limit diagram (FLD) is a popular representation of failure in forming applications. However, the FLD is a good measure of failure only in proportional straining situations, since the forming limit curve (FLC) depends on the straining history, cf. Hosford and Cadell (1993). In recent years, a representation of failure in other types of diagrams has gained popularity. The effective 
Table 2: Parameter setting for constitutive formulation.

\begin{tabular}{lr}
\hline$E[\mathrm{GPa}]$ & 200 \\
$\nu$ & 0.3 \\
$m$ & 6 \\
$\varepsilon_{t}[\%]$ & 12.6 \\
$\sigma_{0}$ & \\
{$[\mathrm{MPa}]$} & 346 \\
$Q_{1}$ & \\
{$[\mathrm{MPa}]$} & 269 \\
$C_{1}$ & 12 \\
$Q_{2}$ & 173 \\
{$[\mathrm{MPa}]$} & 91 \\
$C_{2}$ & -93 \\
$A[\mathrm{MPa}]$ & 1031 \\
$B[\mathrm{MPa}]$ & 0.11 \\
$C$ & \\
$\dot{\varepsilon}_{0}\left[\mathrm{~s}^{-1}\right]$ & $5.675 \cdot 10^{-5}$ \\
$q$ & $8.6 \cdot 10^{-3}$ \\
\hline
\end{tabular}

plastic strain at fracture is often presented as a function of the stress traxiality and the Lode parameter. The stress triaxiality is defined as the ratio between the mean stress and the von Mises equivalent stress, i.e.

$$
\eta=\frac{\sigma_{m}}{\sigma_{v M}}
$$

The mean stress is defined as $\sigma_{m}=\sigma_{i i} / 3$, where $\sigma_{i j}$ is the Cauchy stress component. The von Mises equivalent stress is defined as $\sigma_{v M}=\sqrt{3 / 2 s_{i j} s_{i j}}$, where $s_{i j}$ is the devatoric stress component of the Cauchy stress tensor. The Lode parameter, introduced by Lode (1926), is defined as

$$
\mu=\frac{2 \sigma_{2}-\sigma_{1}-\sigma_{3}}{\sigma_{1}-\sigma_{3}}
$$

where $\sigma_{1}, \sigma_{2}$ and $\sigma_{3}$ are the principal stresses ordered so that $\sigma_{1} \geq \sigma_{2} \geq \sigma_{3}$. From the Lode parameter, an expression independent of the principal stresses can be found, using the second and third deviatoric stress invariants, $J_{2}=\frac{1}{2} s_{i j} s_{i j}$ and $J_{3}=\operatorname{det}\left(s_{i j}\right)$, the Lode angle is defined as

$$
\cos (3 \theta)=\frac{3 \sqrt{3} J_{3}}{2 J_{2}^{3 / 2}}
$$

The Lode angle is the angle between the first principal stress axes and the actual stress state in the $\pi$-plane. The relationship between the Lode parameter, 
$\mu$, and the Lode angle, $\theta$, is

$$
\tan (\theta)=\frac{\sqrt{3}(1+\mu)}{3-\mu}
$$

Most often representations of the fracture are carried out by the use of average values of stress triaxiality and Lode parameters, i.e.

$$
\eta_{\text {avg }}=\frac{1}{\bar{\varepsilon}_{f}^{p}} \int_{0}^{\bar{\varepsilon}_{f}^{p}} \eta\left(\bar{\varepsilon}^{p}\right) \mathrm{d} \bar{\varepsilon}^{p}, \quad \mu_{\text {avg }}=\frac{1}{\bar{\varepsilon}_{f}^{p}} \int_{0}^{\bar{\varepsilon}_{f}^{p}} \mu\left(\bar{\varepsilon}^{p}\right) \mathrm{d} \bar{\varepsilon}^{p}
$$

where $\bar{\varepsilon}_{f}^{p}$ is the effective plastic strain at failure.

\section{Numerical simulation}

Finite element analyses of the tensile, plane strain, in-plane shear and Nakajima experiments were performed with the general purpose FE program LSDYNA, see Hallquist (2009). All simulations have been performed with a physical time scale and both homogeneous and selective mass scaling have been utilised in order to cut computational time. Mass scaling has been carried out so that kinetic energy can be neglected compared to internal energy. All deformations have been applied with a smooth ramp in velocity to minimise dynamic effects. In the shear test model, eight-node brick elements with one integration point and hourglass control have been used in order to cut computational time. However, in all other models eight-node brick elements with a selective reduced integration technique were used. Dense FE meshes have been utilised in all models in order to resolve the strain field and capture instabilities. Typical element sizes in the deformation zone are presented in Table 3. In order to obtain more realistic results, spatial thickness distribution has been given a random variation. Variation in thickness has been introduced as a spatial property independent of the FE mesh. The mean thickness has been set constant in this study and a Gaussian zero mean homogeneous random field, see Shinozuka and Deodatis (1996), has been used for the spatial variation. The parameters representing the random field have been chosen heuristically in order to obtain a thickness variation similar to that observed in measurements.

In order to minimise computational time in the Nakajima tests, a dense FE mesh according to Table 3 has been used in a central region with a transitions to larger elements in remote domains. Since the FE mesh at the clamp is too coarse to predict correct local deformation, the friction coefficient in corresponding parts has been adjusted so that correct in-draw is obtained. The friction coefficient on parts between the punch and specimen was chosen so that a strain response corresponding to the experimental tests were obtained. These strains were evaluated optically on the surface of the specimen in the Nakajima experiments. Shell elements without stiffness (null shells) were added to the upper surface of the FE model of the blank in order to extract the surface strains. 
Data from specific elements has been extracted to investigate the evolution of the stress and strains during the loading process. In the case of the tensile and plane strain specimens, element data has been extracted from the centre parts of the blank both at the top surface and in the middle of the thickness. It was found that the largest strain arises in the middle of the thickness and this data has been used in the evaluation.

In the case of the shear test, the location of failure initialisation is not obvious. Consequently two locations are studied: elements in the specimen in-plane centre and elements at the edge of the specimen close to the major shear zone, see Fig. 11, both on the surface and at the middle of the thickness. It was found that the stress state is almost pure shear in the in-plane centre element during the entire process. For the edge elements, the stress state starts in uniaxial compression but turns towards a pure shear state during the deformation. The largest strains arise in the middle of the sheet thickness for both the in-plane centre and edge elements and, consequently, these locations have been studied further.

For the Nakajima tests, results from the in-plane centre of the blank, both from the top and middle of the thickness, were extracted. In this case the largest strain also arises in the middle of the thickness. In addition, extracted strains from the shell on the top surface have been used to compare with experiments.

Table 3: Typical element sizes of different models.

\begin{tabular}{lrrr} 
Specimen & $l_{x}[\mathrm{~mm}]$ & $l_{y}[\mathrm{~mm}]$ & $l_{z}[\mathrm{~mm}]$ \\
\hline Tensile & 0.33 & 0.46 & 0.30 \\
Plane strain & 0.36 & 0.45 & 0.30 \\
Shear & 0.04 & 0.06 & 0.10 \\
Nakajima, 60-140 mm & 0.33 & 0.66 & 0.49 \\
Nakajima, circular & 0.33 & 0.33 & 0.49 \\
\hline \multicolumn{4}{l}{$l_{x}=$ side length in major loading direction } \\
$l_{y}=$ side length transversal to major loading direction \\
$l_{z}=$ side length in thickness direction
\end{tabular}

\subsection{Identification of fractures in numerical simulations}

In the tensile and plane strain experiments, the instance of a sudden drop in load magnitude during loading has been identified as the instance of fracture. However, for repetitive experiments there is considerable scatter in the displacement at this load drop, and a specific displacement at which fracture occurs is hard to identify. It has been observed from the repetitive experiments that the load magnitude at this load drop is close to identical. Consequently, the load level at this load drop in the experiment is used to identify when fracture occurs in the corresponding simulation. From repetitive experiments, a mean value of the load level at the load drop was evaluated. Thus, when the corresponding load in the simulation result shows a similar drop, fracture is defined as occurring at this instance. 


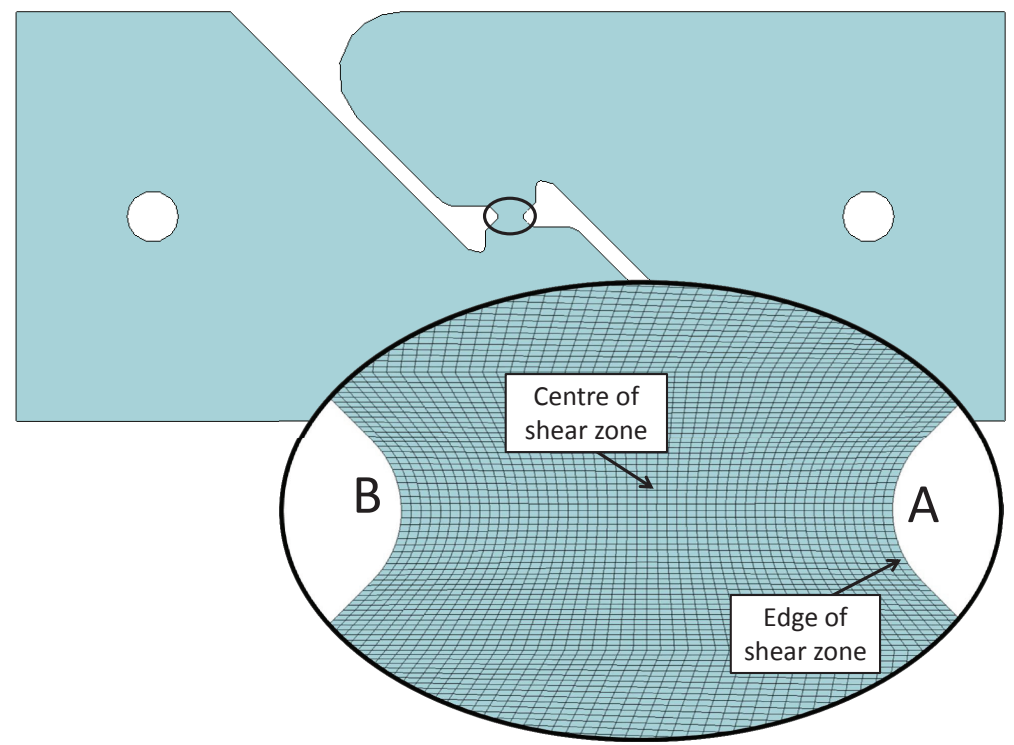

Figure 11: Elements used for extraction of local stresses and strains for the shear test.

In the case of the shear tests, the load drop occurred immediately after maximum load and fracture is assumed to initiate at this instance. Less scatter of the displacement at maximum load occurs in the shear test and the displacement at peak load has been used to identify the fracture initiation. A mean value of the displacements at fracture in the experimental results has been used to identify the corresponding displacement in the simulation results.

In the case of the Nakajima experiments, the strains field was continuously recorded and the maximum principal strain has been identified from this data. Fracture has been assumed to occur when the identical principal strain has been observed at the top surface shell elements. A mean value of these principal strains has been used for further evaluation. However, since the measured strain in the experiments is recorded just before fracture occurs, the fracture strain will be underestimated. Furthermore, since the size of the localisation band is similar to the sheet thickness $(1.5 \mathrm{~mm})$ and since the grid size used for strain evaluation in the experiments is about $2 \mathrm{~mm}$, the strain will be further underestimated. This is especially the case for specimens which develop instability before fracture.

\subsection{Identification of instabilities in numerical simulations}

In order to predict if an instability has occurred, a similar evaluation method as described in Section 2 has been used also on the simulation results. At the moment corresponding to fracture, lines through elements across the specimen have been selected and the principal strains have been evaluated and plotted against their position along the line. The strain points that show a significantly larger major strain compared to their neighbours have been excluded and a polynomial was fitted to the remaining strains. The strain causing instability has then been defined as the maximum strain of this polynomial fit. Instabilities were detected in the simulation results prior to fracture in the case of the tensile, plane strain and 
Nakajima tests with a waist of $60 \mathrm{~mm}$ to $120 \mathrm{~mm}$. This is in agreement with experimental observations. In the case of the Nakajima specimens with waists of $130 \mathrm{~mm}, 140 \mathrm{~mm}$, and for the circular specimens the strain distribution at fracture is evenly distributed and no peaks arise. Consequently instability has been assumed not to occur before fracture in these cases. However, by studying the evolution of the strain at displacements larger than the identified fracture displacement, strain peaks will eventually arise due to instability. At this instance an evaluation, similar to what is described above, has been utilised for comparison purpose, even though fracture already has occurred.

\section{Validation}

Finite element simulations have been conducted in order to evaluate the stress and strain states at the moment of fracture. The simulation results have been compared with experimental results. In the case of the tensile and plane strain tests the nominal stress, $\left(s=F / A_{0}\right)$, and the crosshead displacement from the simulation and experimental results are compared, see Figs. 12(a) and 12(b). In the case of the in-plane shear test the nominal shear stress, $\left(\tau=F / A_{0}\right)$, and the crosshead displacement from the simulation and experimental results are compared, see Fig. 12(c). In the case of the tensile, plane strain and in-plane shear tests the simulations have been conducted both with and without the SRS effect. In the case of the Nakajima tests simulation and experimental results, both the punch force to displacement relationship and the strain paths have been compared, see Figs. 13-19. The agreement obtained is, in general, good for all test cases. However, since an isotropic yield function is used the anisotropy observed in the experiments is not captured in the simulation results. There is also some scatter in the experimental results and only one experiment has been selected as representative for each test case. The instabilities observed in experiments and predicted by simulations of the Nakajima tests are shown in Fig. 20. The strains at an instability, both in experiments and simulations, have been evaluated in a similar way, see Section 2 and 5.2, respectively. In order to identify if any instabilities has occurred in the simulations the relationship between the effective plastic strain rate and the normalised displacement is shown in Fig. 21.

\section{Results and discussion}

Different diagrams are produced to present the failure of the dual phase steel. First a classical FLD is shown, where both the identified instability strains and the final fracture strains identified from the simulation results have been included, see Fig. 22. In addition, the effective plastic strain at fracture is shown as a function of the average stress triaxiality and the average Lode parameter, see Figs. 23 and 24. The relationship between the average stress triaxiality and the average Lode parameter is also shown in Fig. 25. It is to be noted that all points are located close to the plane stress curve. The limit values for the effective plastic strain, average stress triaxiality and average Lode parameter, both at fracture and 


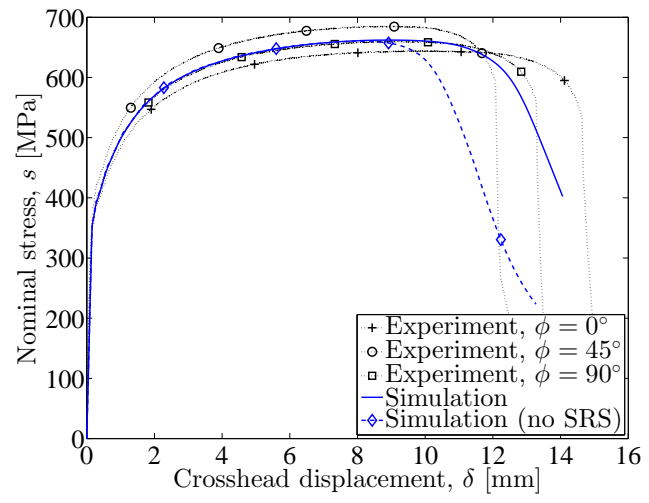

(a)

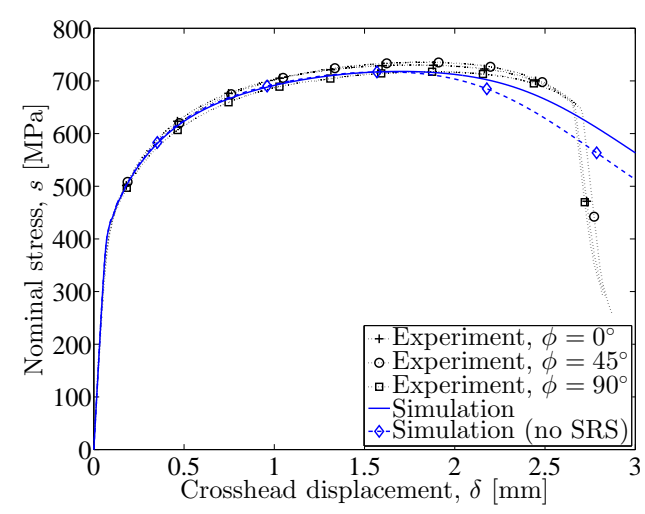

(b)

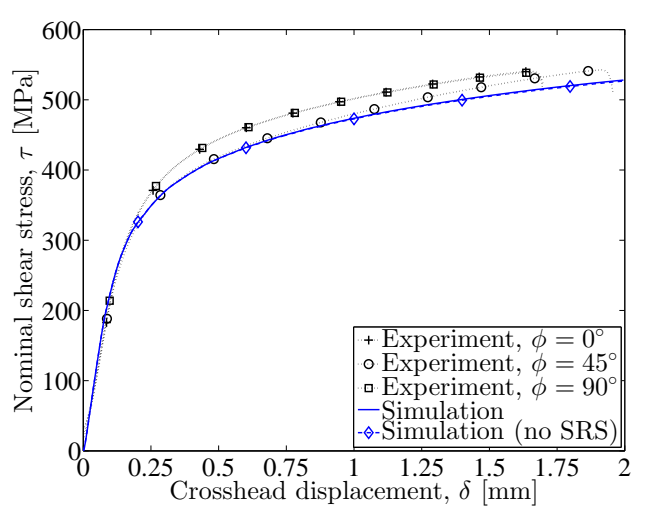

(c)

Figure 12: Nominal stress and crosshead displacement for (a) tensile, (b) plane strain and (c) shear tests.

instability, are presented in Table 4. Trendlines of the fracture and instabilities have been included in the different diagrams. These trendlines are identified by fitting a polynomial to the data. It is to be noted that the point representing the shear test has not been included in the polynomial fit since it belongs to a different failure branch, cf. Fig. 25.

For the Nakajima tests, which did not show an instability, the stress state at fracture at the centre, with respect to the thickness, is presented in Fig. 26. Below follows a discussion of each type of experiment and the corresponding simulation case by case.

\subsection{Tensile test}

In the tensile test, instabilities occur prior to material fracture as observed from experimental results and predicted by the simulations. The simulation is set up such that the strain path is linear until diffuse necking (maximum load) occurs, after which a transition to a plane strain state occurs. The localisation appears in a narrow band after diffuse necking and the increased strain rate causes increased stress locally, which consequently delays the onset of a thickness instability. Results from a simulation without the SRS effect confirm that the loss of load 


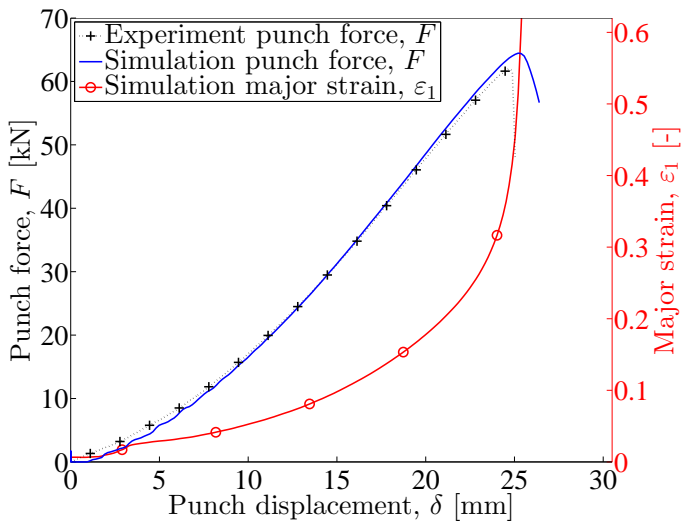

(a)

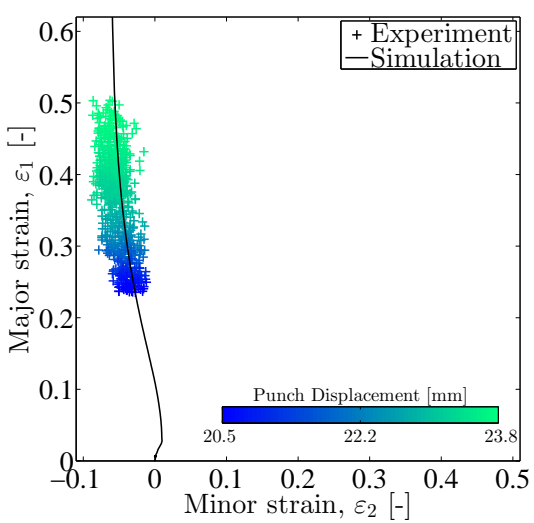

(b)

Figure 13: Results from experiment and FE simulation of the Nakajima test with a waist of 60 mm. (a) Force displacement relationship and evolution of the major strain from the simulation and (b) major and minor strains.

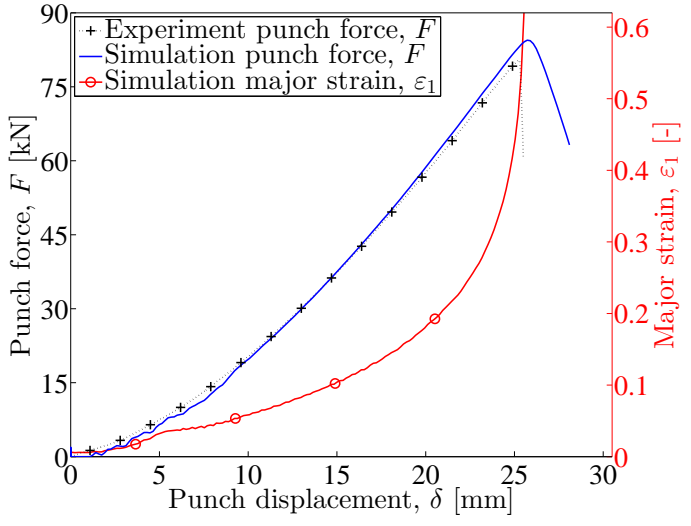

(a)

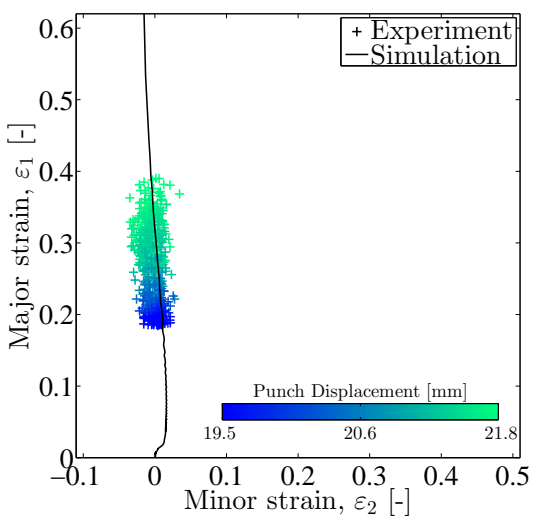

(b)

Figure 14: Results from experiment and FE simulation of the Nakajima test with a waist of 80 $\mathrm{mm}$. (a) Force displacement relationship and evolution of the major strain from the simulation and (b) major and minor strains.

bearing capacity occurs almost immediately after diffuse necking, see Fig. 12(a). Since there is a gradual transition from diffuse to localised necking, it is hard to define a specific limit strain at which localised necking occurs.

At localised necking the strain grows within a small region and, consequently, the strain rate in this region increases rapidly. In Fig. 21(a) the effective plastic strain rate at the centre of the sheet thickness as a function of the normalised crosshead displacement is shown. A rapid increase in strain rate occurs before fracture, due to the local instability.

The onset of instability is predicted by the method described in Section 5.2, and major and minor in-plane strains at the onset of localised instability are shown in Fig. 22. After localisation, the deformation appears in a narrow region and the strain state will be affected by the element size. Even if a mesh refinement 


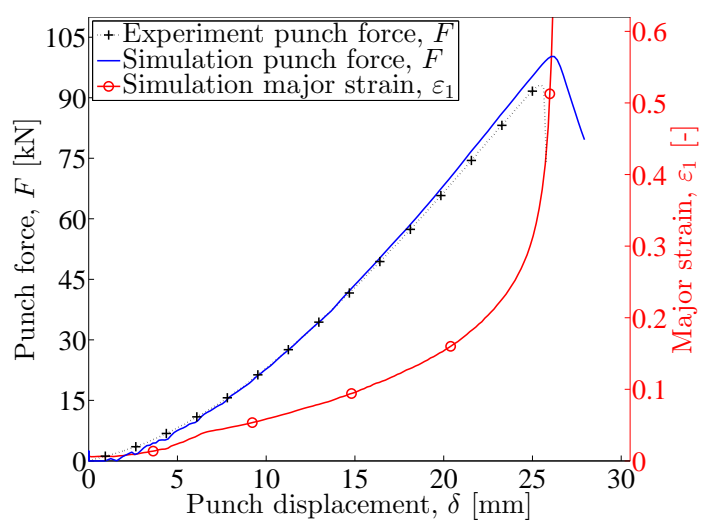

(a)

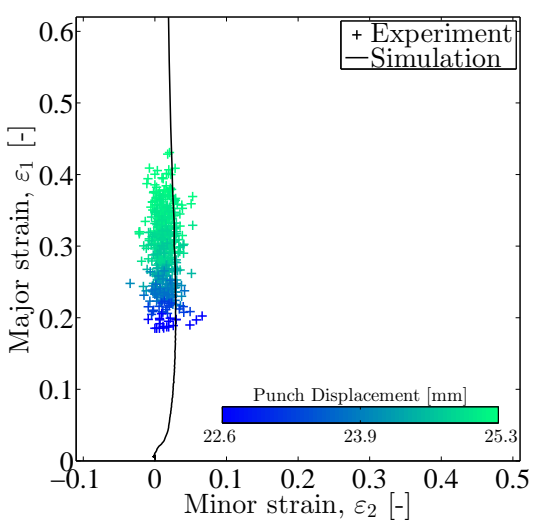

(b)

Figure 15: Results from experiment and FE simulation of the Nakajima test with a waist of 100 mm. (a) Force displacement relationship and evolution of the major strain from the simulation and (b) major and minor strains.

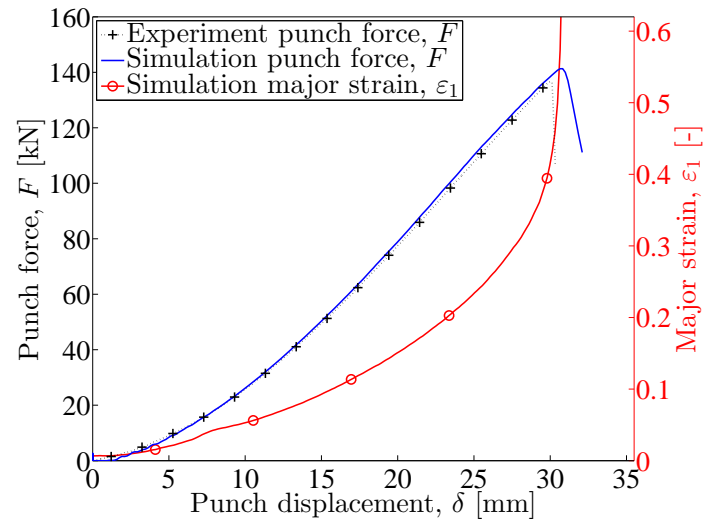

(a)

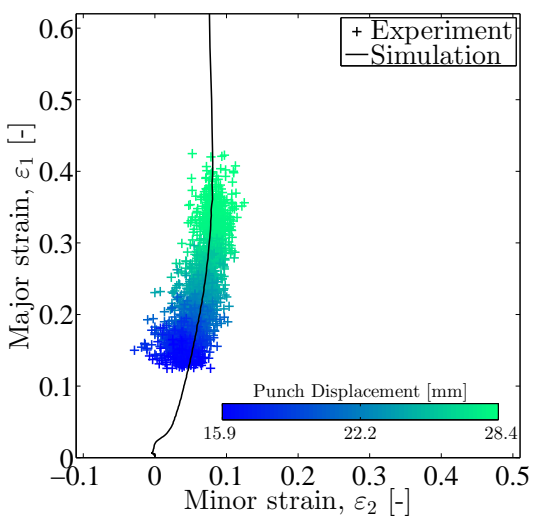

(b)

Figure 16: Results from experiment and FE simulation of the Nakajima test with a waist of 120 mm. (a) Force displacement relationship and evolution of the major strain from the simulation and (b) major and minor strains.

results in approximately the same global force displacement response the strain field within the localized zone is affected. Consequently, the strain at fracture occurring after an instability must be evaluated with great caution.

\subsection{Plane strain test}

In the simulation of the plane strain test, a continuous increase in strain rate is observed at the thickness centre up to fracture, see Fig. 21(a). A rapid increase in strain rate occurs before fracture, which indicates a local instability in the plane strain specimen also. The strain rate increase is not as rapid as in the tensile test. From force displacement prediction, the difference between results involving the SRS and without it is found to be smaller, see Fig. 12(b).

From the simulation it is observed that the strains start to localise at an early 


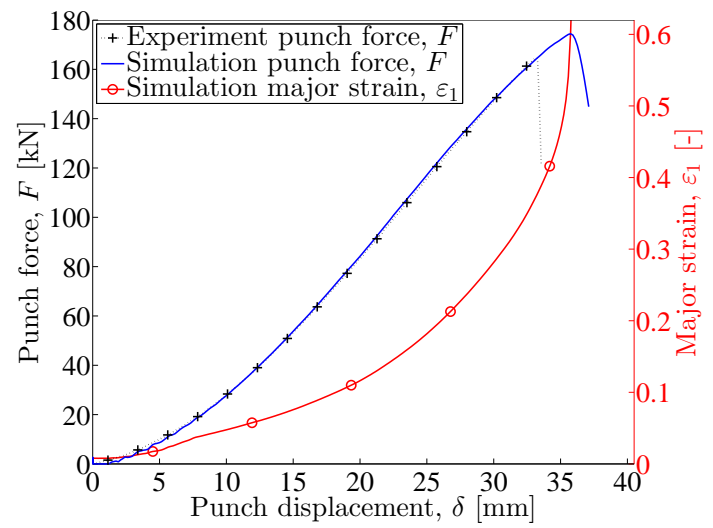

(a)

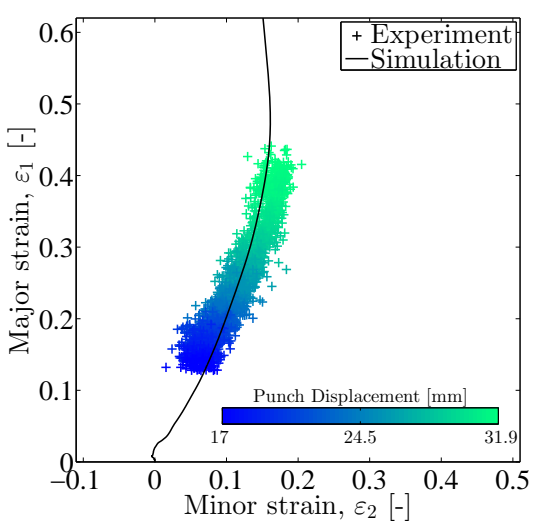

(b)

Figure 17: Results from experiment and FE simulation of the Nakajima test with a waist of 130 mm. (a) Force displacement relationship and evolution of the major strain from the simulation and (b) major and minor strains.

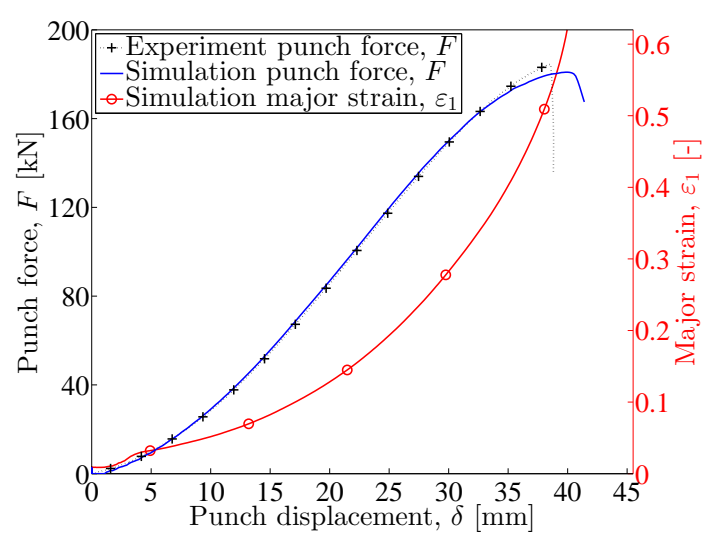

(a)

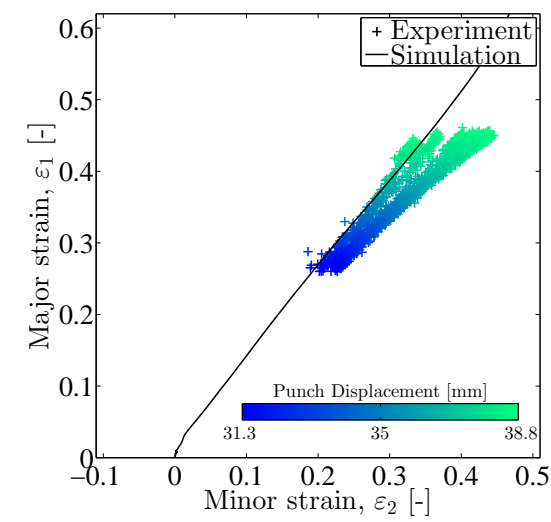

(b)

Figure 18: Results from experiment and FE simulation of the Nakajima test with a waist of 140 mm. (a) Force displacement relationship and evolution of the major strain from the simulation and (b) major and minor strains.

stage. However, the assumed SRS and the specimen geometry cause a distribution of the strains across a larger area, which thereby delays the onset of a localised instability. The method described in Section 5.2 has been used to locate the onset of instability in this test as well, and the major and minor in-plane strains at the onset of localised instability are shown in Fig. 22. Also in this test case, the element size significantly affects the evaluated strain at fracture.

\subsection{Shear test}

No difference between results from simulations taking and not taking the SRS effect into consideration can be observed in the shear test, see Fig. 12(c). In addition no significant increase in the strain rate before fracture is observed, see Fig. 21(a). From these observations it can be concluded that no instability occurs 


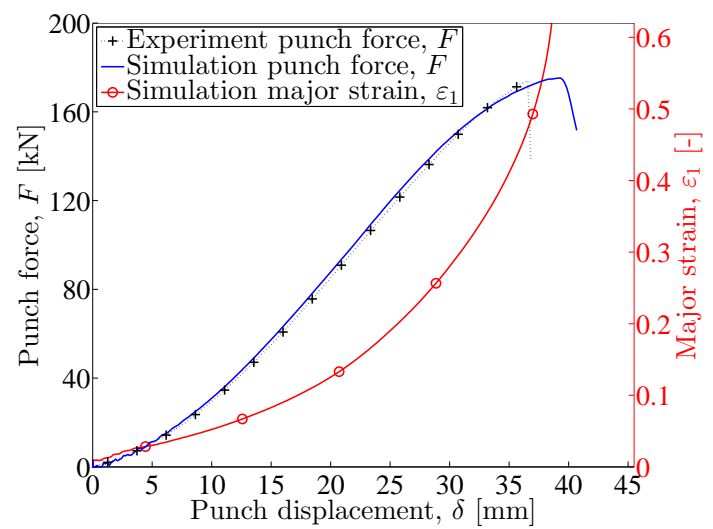

(a)

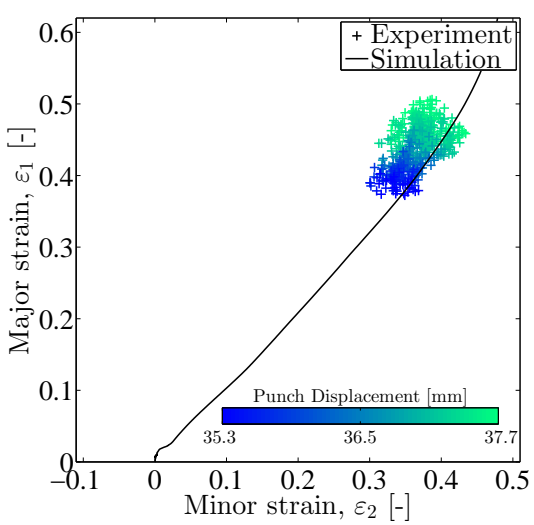

(b)

Figure 19: Results from experiment and FE simulation of the circular Nakajima test. (a) Force displacement relationship and evolution of the major strain from the simulation and (b) major and minor strains.

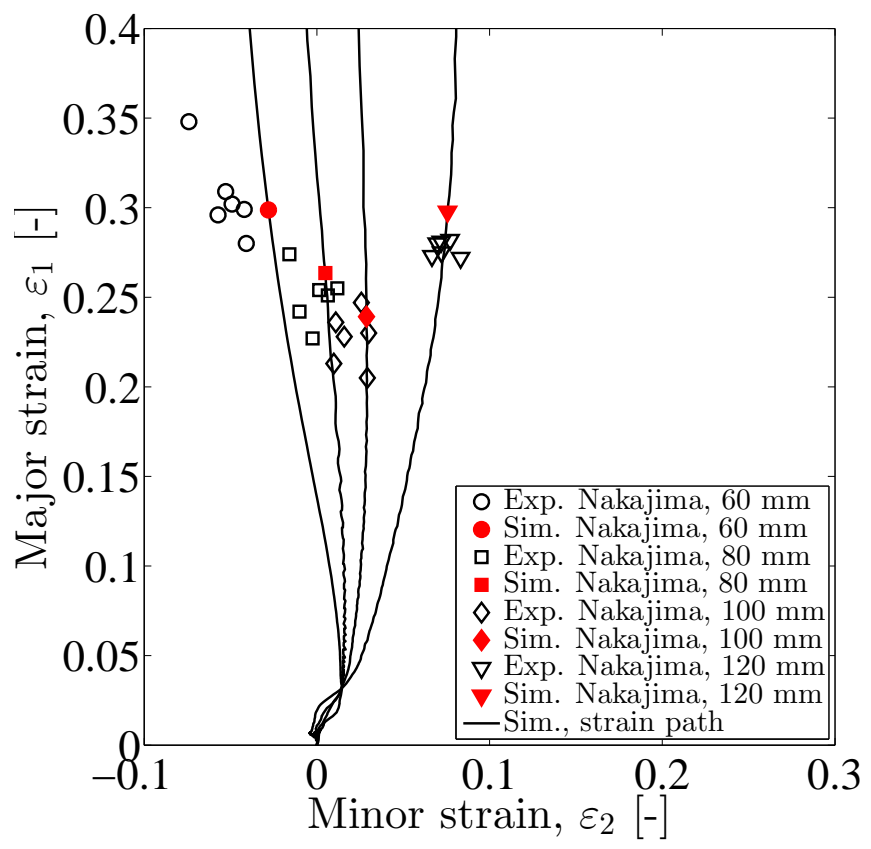

Figure 20: Identified strains at instability from experiments and simulations. The same method has been used to evaluate the strains at instabilities, both from experimental results and simulation results, see Section 2 and 5.2, respectively.

prior to fracture in the shear test. The geometry of the shear test specimen is designed to produce a pure shear zone in the specimen centre. During deformation, however, a rotation of the shear zone takes place. Initially the shear zone is aligned with the loading direction, but it is subsequently rotated approximately $20^{\circ}$ during loading. The loading of the element at edge A, see Fig. 11, of the shear zone starts in an almost pure uniaxial compression. At the in-plane centre, the deformation is in almost pure shear during the entire deformation process. Average values 
of the stress triaxiality and the Lode parameter have been used to characterise the fracture. It is, however, observed that the evolutions of these parameters are significantly nonlinear, see the in-plane centre and edge evolutions in Fig. 27, and a large deviation from average values can be observed. The element size used for the shear test is significantly smaller than that used for the other test specimens, since the deformation to be resolved in this case takes place in a smaller regime. Since no instability is noted, the predicted stress and strain responses at fracture are believed to be accurate.

\subsection{Nakajima tests}

From the LM study of the fracture surface of the Nakajima specimens, a clear difference in fracture appearance is observed between the specimens with a waist of $60 \mathrm{~mm}$ to $120 \mathrm{~mm}$ and those with a waist $130 \mathrm{~mm}$ and larger, see Fig. 6. In specimens with a waist in the range of $60 \mathrm{~mm}$ to $120 \mathrm{~mm}$ a rapid decrease in thickness occurs before fracture, see Fig. 7 and Table 1, which indicates that an instability occurs prior to fracture. Close to fracture, a rapid increase in strain rate in the thickness centre is predicted by the simulations of these specimens, see Fig. 21(b). For the $130 \mathrm{~mm}$ and wider specimens the rapid increase in strain rate occurs at displacements larger than those experimentally observed at fracture. In the experiments no rapid decrease in thickness is observed, see Fig. 7 and Table 1. Thus no instability occurs prior to fracture in these cases. Close-up views of the fracture surfaces using both LM and SEM reveal a difference in appearance of the fracture surface between specimens with a waist of $130 \mathrm{~mm}$ and those with a waist of $140 \mathrm{~mm}$ and larger. In the outermost parts of the fracture zone, a rotation of the grains is observed in the specimens with a waist of $130 \mathrm{~mm}$, see Fig. 8(a). This rotation can be interpreted as an initially shear-dominated fracture process. In the case of the $140 \mathrm{~mm}$ and circular specimens the grains are aligned in the deformation direction, see Figs. 8(b) and 8(c), which indicates a tensile type of fracture. A difference in fracture appearance is also noted in the SEM study, where the $130 \mathrm{~mm}$ specimen shows a smooth fracture surface in contrast to the $140 \mathrm{~mm}$ and circular specimen, where rough surfaces are noted, see Fig. 9. In the case of specimens with a waist of $130 \mathrm{~mm}$ and larger the stress states at the predicted fracture are extracted from the thickness centre, which is illustrated in Fig. 26. It can be seen that the specimen with a waist of $130 \mathrm{~mm}$ shows more pronounced through-thickness shear stresses, $\sigma_{y z}$ and $\sigma_{z x}$, compared to the specimen with a waist of $140 \mathrm{~mm}$ and the circular one.

\subsection{Forming limit diagram}

The major and minor strains at instability and fracture, predicted from the simulation results, are presented in Fig. 22. The minimum of the forming limit curve, FLC, occurs in the positive quadrant (both principal strains positive) and

can be explained by the nonlinear strain evolution in the Nakajima tests. The predicted instabilities can be represented in the FLD by a linear curve to the left of the FLC minimum, see Fig. 22. However, the strain at fracture in the same FLD region is significantly higher for the tensile and plane strain tests. As 
previously mentioned, the strain state at fracture is significantly affected by the element size for specimens that are subjected to an instability before fracture and the fracture strain trend line is less accurate than the FLC. In this work the element size is about the same for all test specimens except for the shear test specimen. The strain at fracture in the Nakajima test simulation is chosen as the strain just before the fracture appears in the experiment. Since the strain rate after instability grows large, the fracture strain may be slightly under-predicted.

On the right side of the minimum of the FLC a higher order polynomial is used to describe the onset of instability. For specimens, which did not show an instability prior to material fracture, a point of instability has been identified from the simulation results under the assumption of an unfractured specimen, see Section 5.2. From the FLD, an intersection between the instability locus and the fracture locus is noted. This intersection occurs at a strain state between those of the Nakajima test specimens with waist of $120 \mathrm{~mm}$ and $130 \mathrm{~mm}$.

\subsection{Effective plastic strain}

The effective plastic strain at instability and fracture as a function of the average stress triaxiality $\eta_{\text {avg }}$, see Eq. (10), and the average Lode parameter $\mu_{\text {avg }}$, see Eq. (10), is displayed in Figs. 23 and 24, respectively. The effective plastic strain at instability and at fracture show a strong dependency on the average stress triaxiality for stress states between uniaxial tension and biaxial tension, i.e. $\frac{1}{3} \leq \eta_{\text {avg }} \leq \frac{2}{3}$. In the case of instability, the effective plastic strains decrease rapidly above $\eta_{\text {avg }}=\frac{1}{3}$ with smaller values in the region $0.45<\eta_{\text {avg }}<0.57$. Thereafter a rapid increase in the effective plastic strain occurs. The effective plastic strain at fracture has a similar appearance. The effective plastic strain at fracture has its smallest value in the range $0.46<\eta_{\text {avg }}<0.60$. It is noted that the effective plastic strain at instability and fracture more or less coincide for $0.60<\eta_{\text {avg }} \leq \frac{2}{3}$. When the effective plastic strain is shown as a function of the average Lode parameter, see Fig. 24, it is noted that instability occurs prior to fracture if $\mu \leq 0.5$. However, this is not observed in the shear test as this fracture belongs to a different Lode parameter branch, see Fig. 25. For Lode parameter values $\mu_{\text {avg }}>0.5$ a fracture is presumed to occur before instability. It is noted that a minimum in effective plastic strain occurs when $\mu_{\text {avg }} \approx 0.0$, both for effective plastic strains at instability and fracture, and these values corresponds to a Lode angle of approximately $30^{\circ}$. 
Table 4: Average stress triaxiality and Lode parameter at the effective strain at fracture and instability.

\begin{tabular}{lcccccc} 
Specimen & \multicolumn{3}{c}{ Fracture } & \multicolumn{3}{c}{ Instability } \\
\cline { 2 - 7 } & $\bar{\varepsilon}^{p}$ & $\eta_{\text {avg }}$ & $\mu_{\text {avg }}$ & $\bar{\varepsilon}^{p}$ & $\eta_{\text {avg }}$ & $\mu_{\text {avg }}$ \\
\hline Tensile & 0.86 & 0.441 & -0.713 & 0.65 & 0.394 & -0.813 \\
Plane Strain & 0.56 & 0.578 & -0.177 & 0.27 & 0.524 & -0.28 \\
Shear (centre) & 0.77 & 0.095 & -0.153 & & & \\
Shear (edge) & 1.03 & -0.496 & 0.168 & & & \\
Nakajima, 60 mm & 0.45 & 0.484 & -0.341 & 0.28 & 0.465 & -0.366 \\
Nakajima, 80 mm & 0.4 & 0.526 & -0.123 & 0.26 & 0.523 & -0.062 \\
Nakajima, 100 mm & 0.41 & 0.560 & 0.115 & 0.24 & 0.572 & 0.238 \\
Nakajima, 120 mm & 0.44 & 0.620 & 0.464 & 0.36 & 0.621 & 0.515 \\
Nakajima, 130 mm & 0.55 & 0.629 & 0.700 & $0.62^{*}$ & $0.630^{*}$ & $0.680^{*}$ \\
Nakajima, 140 mm & 0.72 & 0.638 & 0.877 & $0.84^{*}$ & $0.640^{*}$ & $0.880^{*}$ \\
Nakajima, circular & 0.79 & 0.650 & 0.943 & $0.85^{*}$ & $0.650^{*}$ & $0.940^{*}$ \\
\hline
\end{tabular}

* Instability after point of fracture

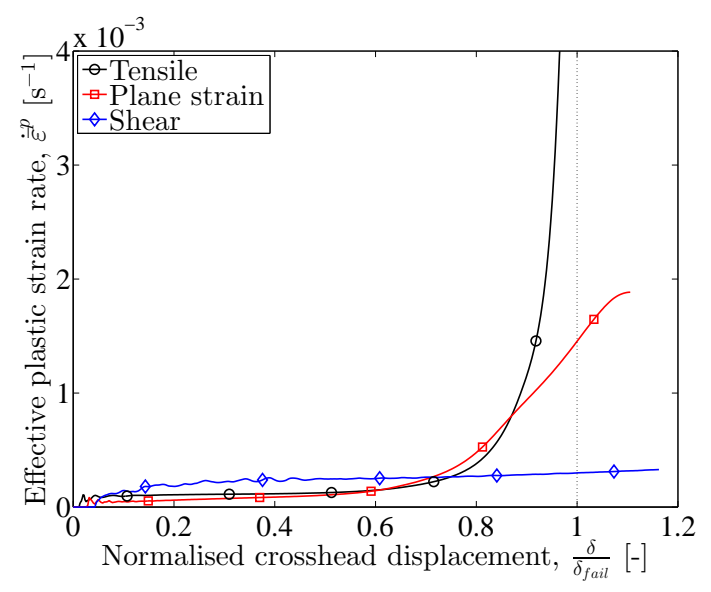

(a)

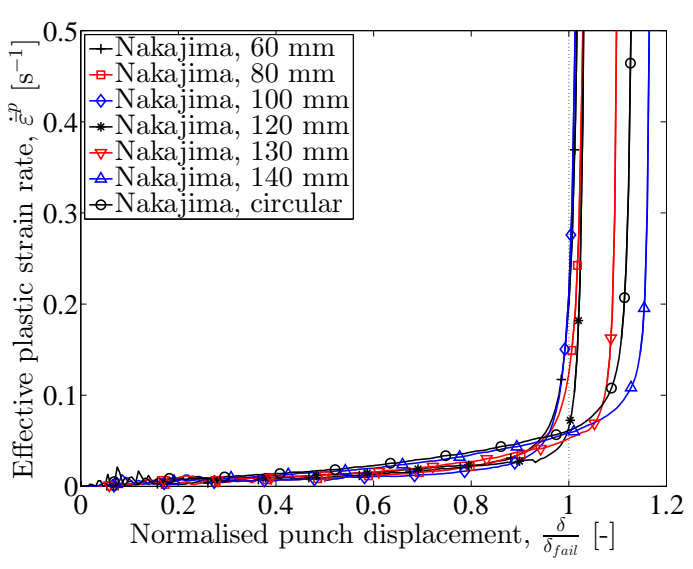

(b)

Figure 21: Strain rates obtained from simulations. The displacements have been normalised with respect to the displacement at fracture in the experiments (a) tensile, plane strain and shear tests and (b) Nakajima tests with waists from $60 \mathrm{~mm}$ to circular. 


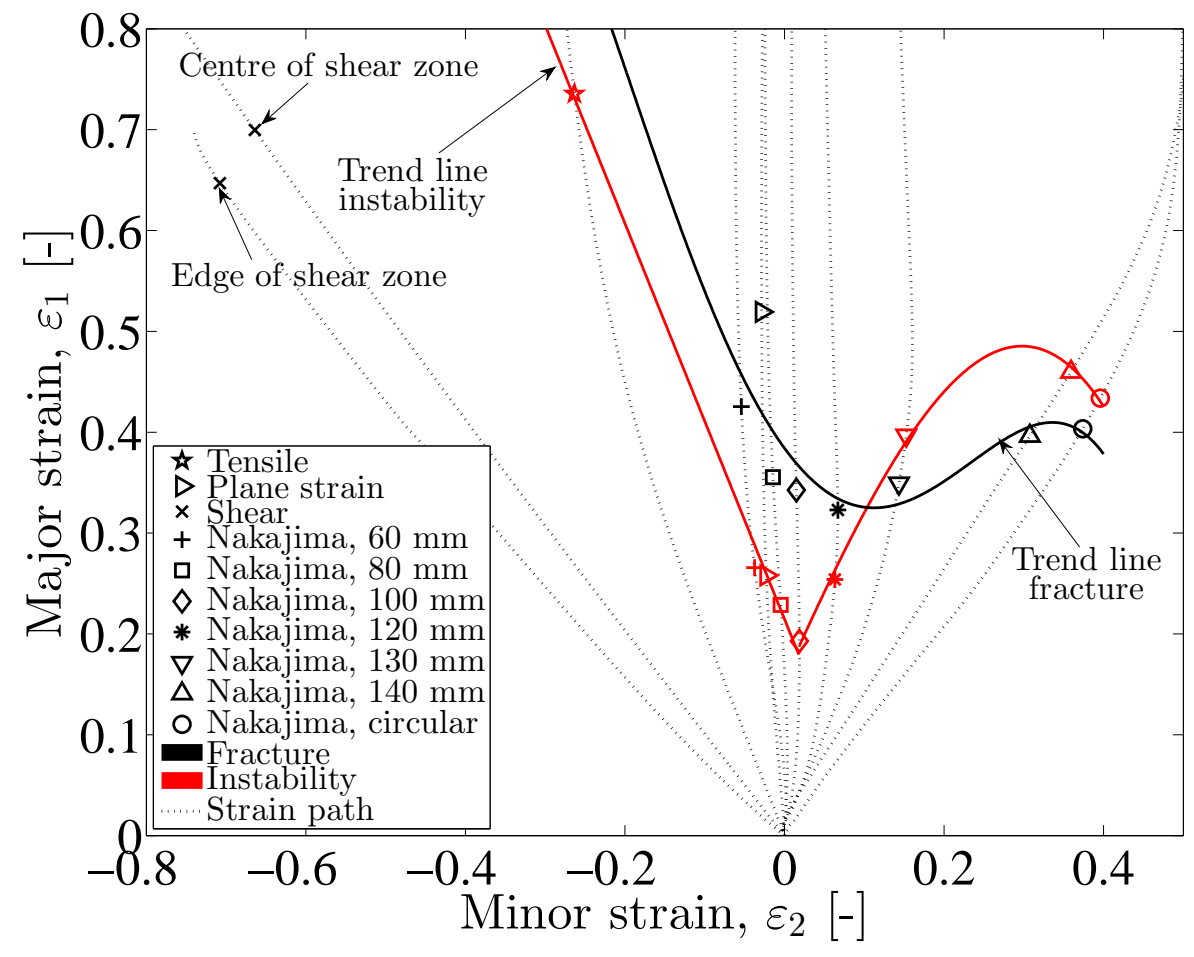

Figure 22: Representation of fracture and instability in the forming limit diagram (FLD).

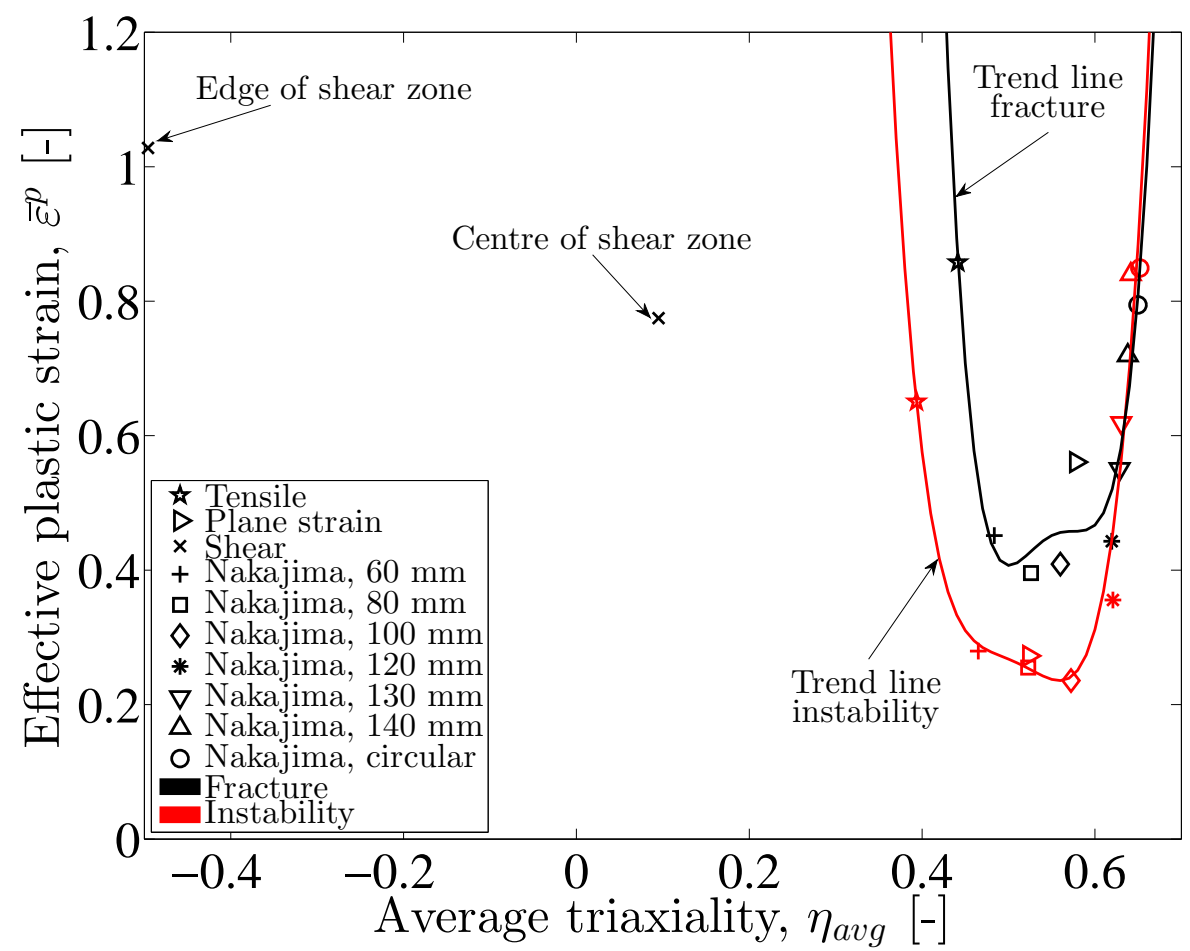

Figure 23: Representation of fracture and instability in the space of the effective plastic strain and the average stress triaxiality. 


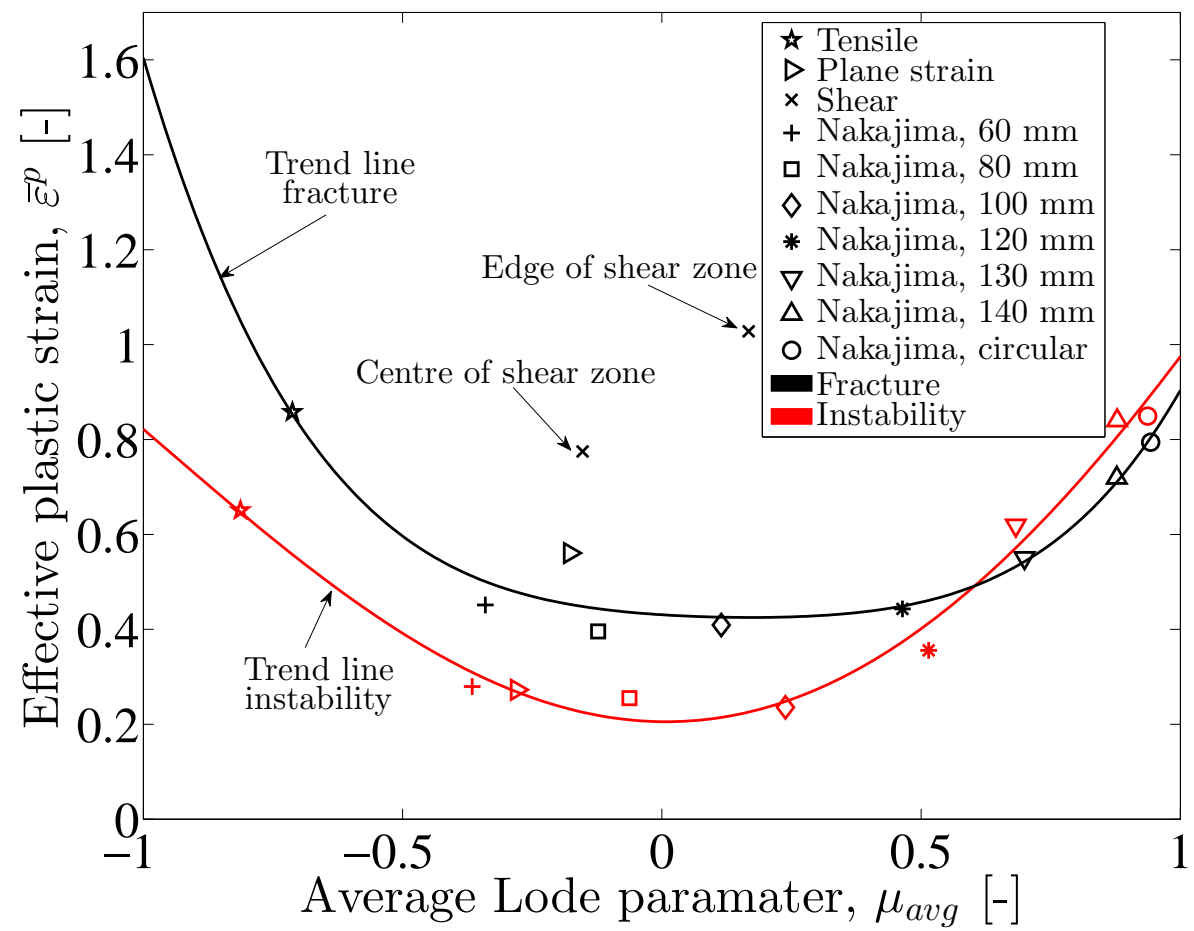

Figure 24: Representation of fracture and instability in the space of the effective plastic strain and the average Lode parameter.

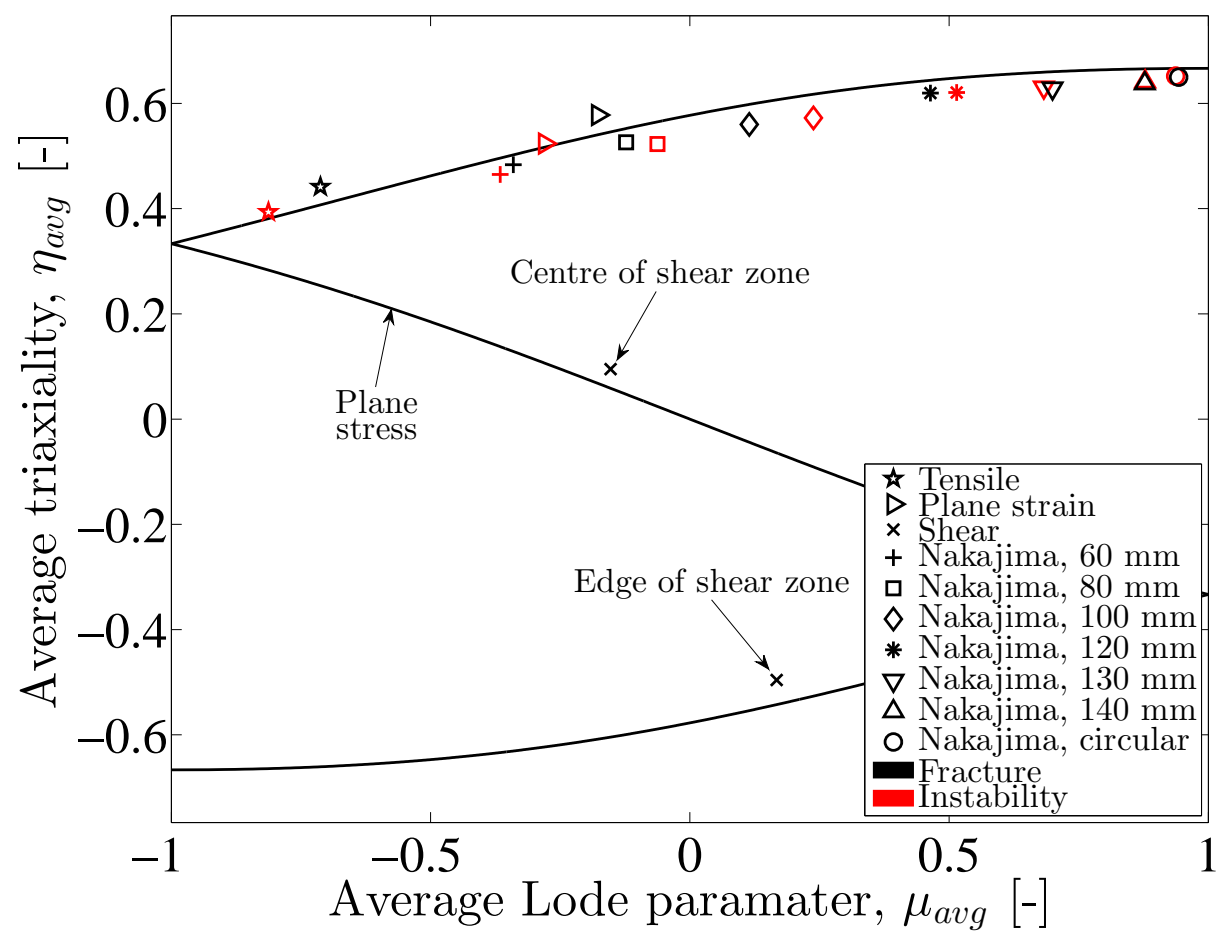

Figure 25: Representation of fracture and instability in the space of the average stress triaxiality and the average Lode parameter. 


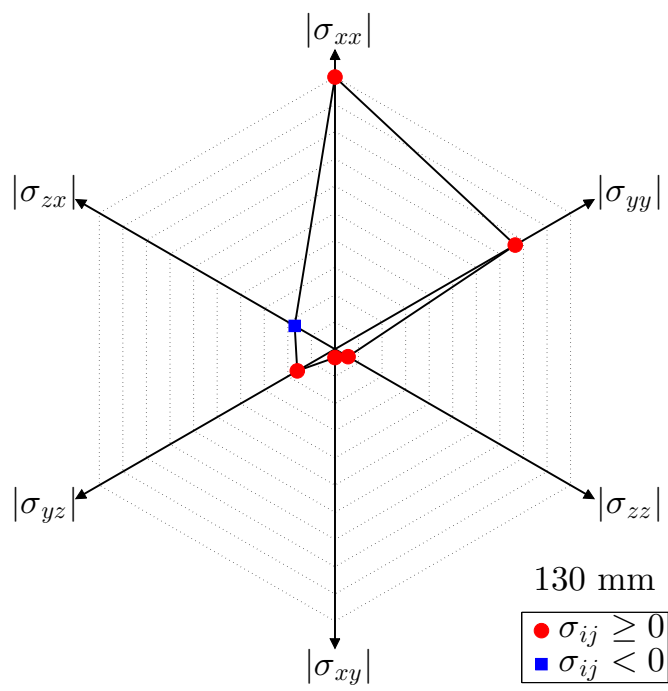

(a)

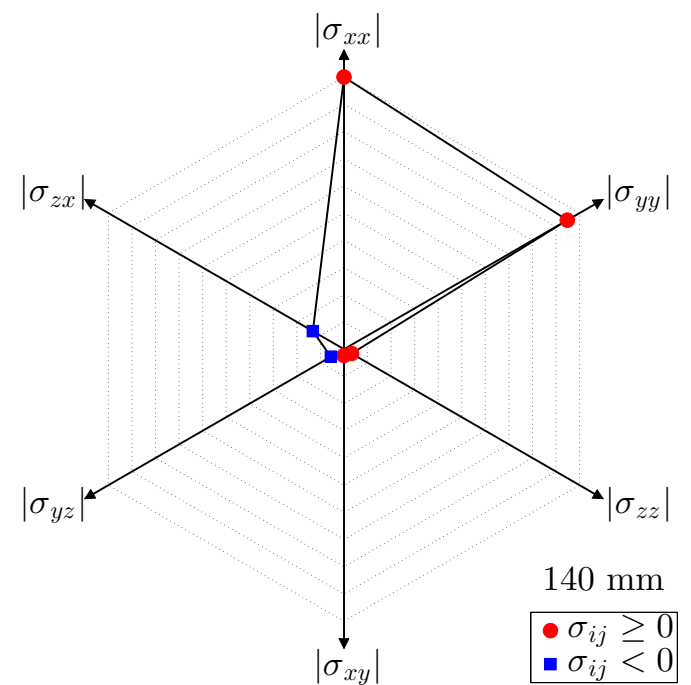

(b)

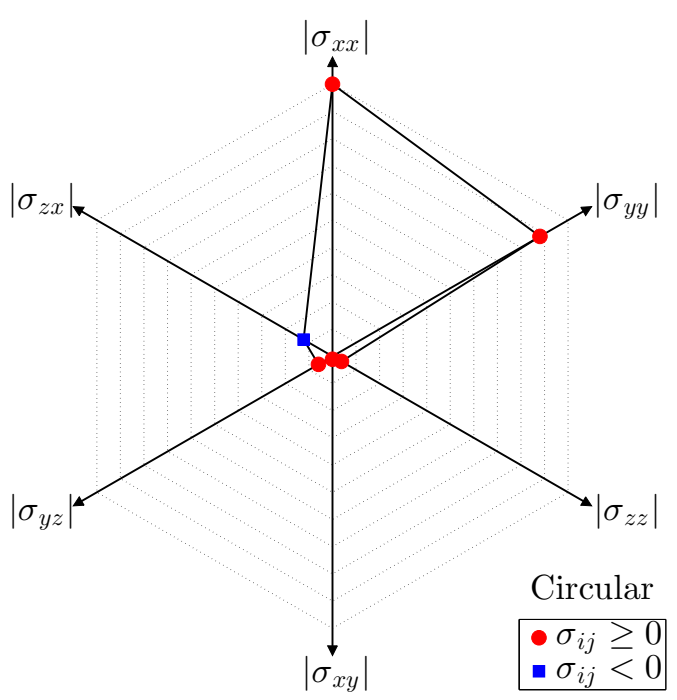

(c)

Figure 26: Stress state at failure for specimens with a waist of (a) $130 \mathrm{~mm}$, (b) $140 \mathrm{~mm}$ and (d) circular.

\section{Conclusions}

The major objective of this study was to identify the type of fracture occurring in Nakajima experiments designed for different straining situations. Three different failure phenomena are considered plastic instability, ductile tensile fracture and ductile shear fracture. Microscopic investigations reveal that the Nakajima specimens with a waist of $60 \mathrm{~mm}$ to $120 \mathrm{~mm}$ fail after a thickness instability, see Fig. 6. This is also confirmed by FE studies. After instability, the strains will be localised to a narrow band and the final fracture will appear immediately afterwards, either due to ductile tensile or ductile shear fracture. However, no attempt was made to find the mechanism causing fracture that succeeded the instability. 


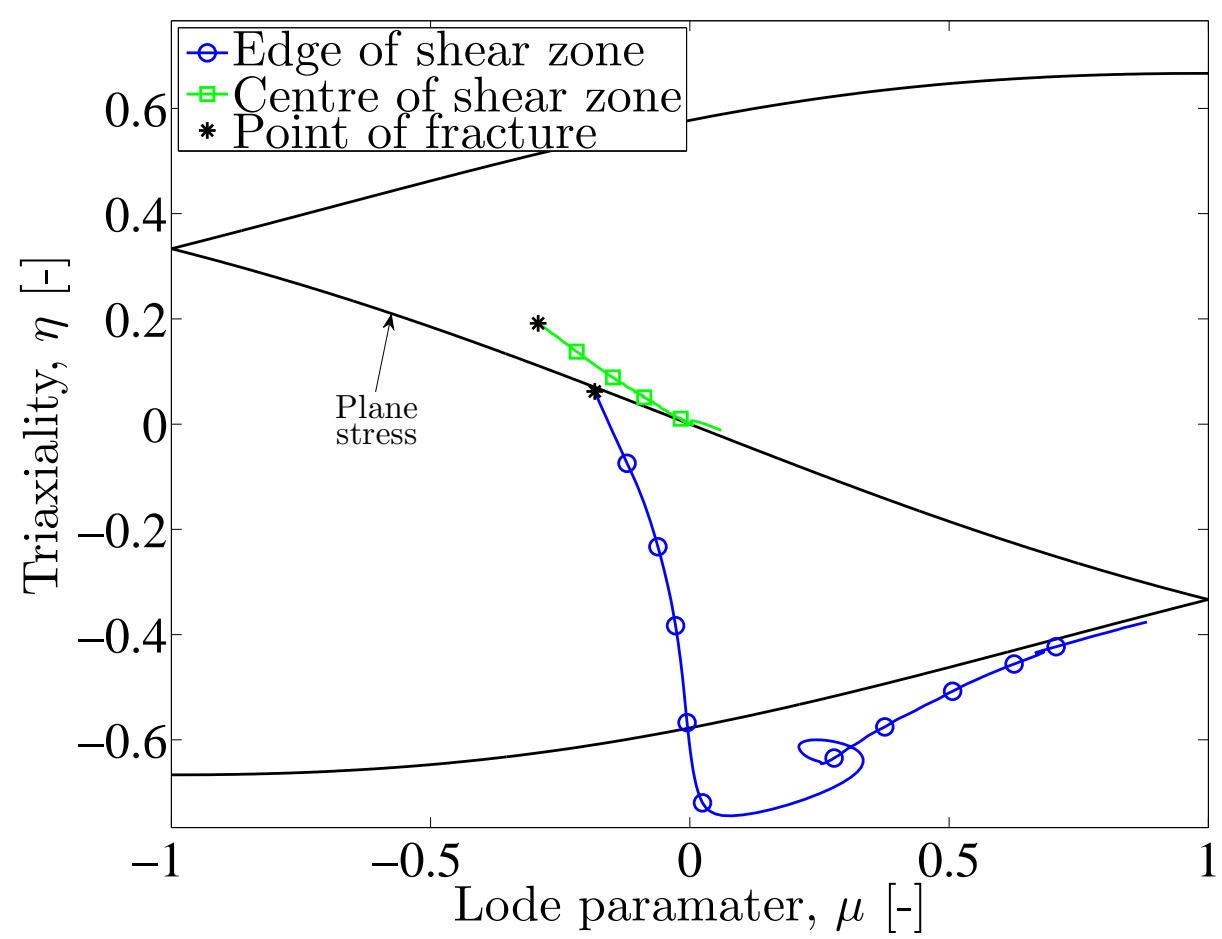

Figure 27: Deformation path in the stress triaxiality and the Lode parameter space from the shear test specimen at in-plane centre and edge of fracture zone. Both paths are obtained from the middle of the sheet thickness.

When fractures appeared without any sign of instability in the Nakajima specimens, a closer microscopic investigation of the fracture surface was undertaken. In the case of the Nakajima specimen with a waist of $130 \mathrm{~mm}$, the fracture was identified as driven mainly by shear stresses and for the specimens with a waist of $140 \mathrm{~mm}$ and the circular tensile stresses are believed to cause the fracture, see Fig. 8. The same conclusions were also drawn from the SEM study, see Fig. 9, where the fracture surface of the specimens with a waist of $130 \mathrm{~mm}$ shows a flat appearance and the circular specimen shows a more rough appearance. It can also be noted that the shear stresses through the thickness are larger for the $130 \mathrm{~mm}$ waist specimen relative to the $140 \mathrm{~mm}$ and circular specimens, see Fig. 26. However, the study of the stress triaxiality and Lode parameter shows no remarkable difference between the Nakajima specimen with a waist of $130 \mathrm{~mm}$, which shows ductile shear fracture, and the specimen with a waist of $140 \mathrm{~mm}$ and the circular specimen, which show ductile tensile fracture, see Figs. 23 to 25. Concerning the prediction of effective plastic strain at failure as a function of the average stress triaxiality and the average Lode parameter, it is noted that the deformation paths are significantly nonlinear for most of the tests. A calibration method using inverse modelling is preferable in order to predict the fracture using phenomelogical failure models. To predict material instabilities, the FE method is an important tool. It has, however, been observed that the SRS effect is important and needs to be considered in order to achieve an accurate failure prediction. 


\section{Acknowledgements}

The work presented in this paper has been carried out with financial support from the SSF ProViking project "SuperLight Steel Structures". Annethe Billenius and Per Johansson are acknowledged for guidelines and specimen preparation concerning the microscopic study. The assistance and resources provided by the National Supercomputer Centre, NSC, in Linköping Sweden, have been appreciated.

\section{References}

Aretz, H., 2004. Numerical restrictions of the modified maximum force criterion for prediction of forming limits in sheet metal forming. Modelling and Simulation in Materials Science and Engineering 12 (4), 677-692.

Aretz, H., 2005. A non-quadratic plane stress yield function for orthotropic sheet metals. Journal of Materials Processing Technology 168 (1), 1-9.

Aretz, H., Keller, S., Engler, O., Brinkman, H.-J., 2013. A simple ductile failure model with application to AA5182 aluminium sheet forming. International Journal of Material Forming, $1-16$.

Aretz, H., Keller, S., Vogt, R., Engler, O., 2011. Modelling of ductile failure in aluminium sheet forming simulation. International Journal of Material Forming 4 (2), 163-182.

Bai, Y., Wierzbicki, T., 2010. Application of extended Mohr-Coulomb criterion to ductile fracture. International Journal of Fracture 161, 1-20.

Bao, Y., Wierzbicki, T., 2004. On fracture locus in the equivalent strain and stress triaxiality space. International Journal of Mechanical Sciences 46 (1), 81-98.

Barsoum, I., Faleskog, J., 2007a. Rupture mechanisms in combined tension and shear - experiments. International Journal of Solids and Structures 44 (6), 1768-1786.

Barsoum, I., Faleskog, J., 2007b. Rupture mechanisms in combined tension and shear - micromechanics. International Journal of Solids and Structures 44 (17), 5481-5498.

Björklund, O., Larsson, R., Nilsson, L., 2013. Failure of high strength steel sheets: Experiments and modelling. Journal of Materials Processing Technology 213 (7), 1103-1117.

Bragard, A., Baret, J.-C., Bonnarnes, H., 1972. A simplified technique to determine the FLD at the onset of necking. Report No. 33, Rapport Centre de Recherche de la Mètallurgie, Liège.

Cockroft, M. G., Latham, D. J., 1968. Ductility and the workability of metals. Journal of the Institute of Metals 96, 33-39.

Dieter, G. E., 1986. Mechanical Metallurgy. McGraw-Hill, New York.

Dunand, M., Mohr, D., 2011. On the predictive capabilities of the shear modified gurson and the modified mohr-coulomb fracture models over a wide range of stress triaxialities and lode angles. Journal of the Mechanics and Physics of Solids 59 (7), 1374-1394.

Ebnoether, F., Mohr, D., 2013. Predicting ductile fracture of low carbon steel sheets: Stressbased versus mixed stress/strain-based mohr-coulomb model. International Journal of Solids and Structures 50 (7-8), 1055-1066.

Garrison Jr, W., Moody, N., 1987. Ductile fracture. Journal of Physics and Chemistry of Solids 48 (11), 1035-1074.

Gruben, G., Fagerholt, E., Hopperstad, O., Børvik, T., 2011. Fracture characteristics of a coldrolled dual-phase steel. European Journal of Mechanics - A/Solids 30 (3), 204-218.

Gruben, G., Hopperstad, O., Børvik, T., 2012. Evaluation of uncoupled ductile fracture criteria for the dual-phase steel Docol 600DL. International Journal of Mechanical Sciences 62 (1), $133-146$.

Gruben, G., Hopperstad, O., Børvik, T., 2013. Simulation of ductile crack propagation in dualphase steel. International Journal of Fracture 180 (1), 1-22. 
Gurson, A., 1977. Continuum theory of ductile rupture by void nucleation and growth: Part I Yield criteria and flow rules for porous ductile media. Journal of Engineering Materials and Technology 99 (1), 2-15.

Hallquist, J., 2009. LS-DYNA Theory Manual. Livermore Software Technology Corporation, Livermore.

Hershey, A. V., 1954. The plasticity of an isotropic aggregate of anisotropic face-centered cubic crystals. Journal of Applied Mechanics 21, 241-249.

Hill, R., 1952. On discontinuous plastic states, with special reference to localized necking in thin sheets. Journal of the Mechanics and Physics of Solids 1 (1), 19-30.

Hollomon, J. H., 1945. Tensile deformation. Transaction of the American Institute of Mining, Metallurgical and Petroleum Engineers 162, 268-290.

Hora, P., Tong, L., Reissner, J., 1996. A prediction method for ductile sheet metal failure in FE-simulation. Proceedings of the 3rd International Conference Numisheet'96, Dearborn, Michigan, 252-256.

Hosford, W., Cadell, R., 1993. Metal Forming Mechanics and Metallurgy. Prentis-Hall, New York.

Hosford, W. F., 2005. Mechanical Behavior of Materials. Cambridge University Press, New York. ISO, 2008. Metallic materials -sheet and strip - determination of Forming Limit Curves - Part 2: Determination of Forming Limit Curves in the Laboratory. Austrian Standards Institute, Wien, 12004-2:2008.

Johnson, G. R., Cook, W. H., 1985. Fracture characteristics of three metals subjected to various strains, strain rates, temperatures and pressures. Engineering Fracture Mechanics 21 (1), 31-48.

Kim, J., Sung, J., Piao, K., Wagoner, R., 2011. The shear fracture of dual-phase steel. International Journal of Plasticity 27 (10), 1658-1676.

Lademo, O.-G., Engler, O., Keller, S., Berstad, T., Pedersen, K., Hopperstad, O., 2009. Identification and validation of constitutive model and fracture criterion for AlMgSi alloy with application to sheet forming. Materials and Design 30 (8), 3005-3019.

Lademo, O.-G., Pedersen, K. O., Berstad, T., Hopperstad, O. S., 2004. A numerical tool for formability analysis of aluminium alloys. Part II: Experimental validation. Steel Grips 2, 433-437.

Larsson, R., Björklund, O., Nilsson, L., Simonsson, K., 2011. A study of high strength steels undergoing non-linear strain paths - experiments and modelling. Journal of Materials Processing Technology 211, 122-132.

Larsson, R., 2012. On Material Modelling of High Strength Steel Sheets. Ph.D. Thesis, Linköping University, Linköping.

Lemaitre, J., 1985. A continuous damage mechanics model for ductile fracture. Journal of Engineering Materials and Technology 107, 83-89.

Lemaitre, J., Chaboche, J.-L., 1990. Mechanics of Solid Materials. Cambridge University Press, Cambridge.

Li, H., Fu, M., Lu, J., Yang, H., 2011. Ductile fracture: Experiments and computations. International Journal of Plasticity 27 (2), 147-180.

Li, Y., Luo, M., Gerlach, J., Wierzbicki, T., 2010. Prediction of shear-induced fracture in sheet metal forming. Journal of Materials Processing Technology 210 (14), 1858-1869.

Lode, W., 1926. Versuche über den einfluß der mittleren hauptspannung auf das fließen der metalle eisen, kupfer und nickel. Zeitschrift für Physik 36, 913-939.

Lou, Y., Huh, H., 2013a. Extension of a shear-controlled ductile fracture model considering the stress triaxiality and the Lode parameter. International Journal of Solids and Structures $50(2), 447-455$.

Lou, Y., Huh, H., 2013b. Prediction of ductile fracture for advanced high strength steel with a new criterion: Experiments and simulation. Journal of Materials Processing Technology 213 (8), 1284-1302. 
Lou, Y., Huh, H., Lim, S., Pack, K., 2012. New ductile fracture criterion for prediction of fracture forming limit diagrams of sheet metals. International Journal of Solids and Structures 49 (25), $3605-3615$.

Luo, M., Wierzbicki, T., 2010. Numerical failure analysis of a stretch-bending test on dualphase steel sheets using a phenomenological fracture model. International Journal of Solids and Structures 47 (22-23), 3084-3102.

Marciniak, Z., Kuczyński, K., 1967. Limit strains in the processes of stretch-forming sheet metal. International Journal of Mechanical Sciences 9 (9), 609-620.

McClintock, F. A., 1968. A criterion for ductile fracture by the growth of holes. Journal of Applied Mechanics 35, 363-371.

Metals Handbook, 1974. Interpretation of Transmission-Electron-Microscope Fractographs, in Metals Handbook, 8th Ed., Vol. 9. American Society for Metals, Metals Park.

Mirone, G., Corallo, D., 2010. A local viewpoint for evaluating the influence of stress triaxiality and Lode angle on ductile failure and hardening. International Journal of Plasticity 26 (3), 348-371.

Nielsen, K. L., Tvergaard, V., 2009. Effect of a shear modified gurson model on damage development in a FSW tensile specimen. International Journal of Solids and Structures 46 (3-4), $587-601$.

Olsson, K., Gladh, M., Hedin, J.-E., Larsson, J., 2006. Microalloyed high-strength steels. Advanced Materials and Processes 164 (8), 44-46.

Pedersen, K., Lademo, O.-G., Berstad, T., Furu, T., Hopperstad, O., 2008. Influence of texture and grain structure on strain localisation and formability for almgsi alloys. Journal of Materials Processing Technology 200 (1-3), 77-93.

Rice, J., Tracey, D., 1969. On the ductile enlargement of voids in triaxial stress fields. Journal of the Mechanics and Physics of Solids 17 (3), 201-217.

Shinozuka, M., Deodatis, G., 1996. Simulation of multi-dimensional Gaussian stochastic fields by spectral representation. Applied Mechanics Reviews 49, 29-53.

Stoughton, T. B., 2000. A general forming limit criterion for sheet metal forming. International Journal of Mechanical Sciences 42 (1), 1-27.

Stoughton, T. B., Yoon, J. W., 2011. A new approach for failure criterion for sheet metals. International Journal of Plasticity 27 (3), 440-459.

Stoughton, T. B., Yoon, J. W., 2012. Path independent forming limits in strain and stress spaces. International Journal of Solids and Structures 49 (25), 3616-3625.

Swift, H. W., 1952. Plastic instability under plane strain. Journal of the Mechanics and Physics of Solids, 1, 1-18.

Tarigopula, V., Langseth, M., Hopperstad, O., Clausen, A., 2006. Axial crushing of thin-walled high-strength steel sections. International Journal of Impact Engineering 32 (5), 847-882.

Teirlinck, D., Zok, F., Embury, J., Ashby, M., 1988. Fracture mechanism maps in stress space. Acta Metallurgica 36 (5), 1213-1228.

Voce, E., 1948. The relationship between stress and strain for homogenus deformation. Journal of the Institute of Metals 74, 537-562.

Weck, A., Wilkinson, D., 2008. Experimental investigation of void coalescence in metallic sheets containing laser drilled holes. Acta Materialia 56 (8), 1774-1784.

Wierzbicki, T., Bao, Y., Lee, Y.-W., Bai, Y., 2005. Calibration and evaluation of seven fracture models. International Journal of Mechanical Sciences 47 (4-5), 719-743.

Zhang, K., Bai, J., François, D., 2001. Numerical analysis of the influence of the lode parameter on void growth. International Journal of Solids and Structures 38, 5847-5856. 